\title{
Recidivism After a Prison-Based Treatment Program: a Comparison Between a Treatment and Control Group Using Proportional Weighting Within Strata
}

\author{
Anouk Q. Bosma ${ }^{1}$ • Maarten J. J. Kunst ${ }^{1}$ • Anja J. E. Dirkzwager ${ }^{2}$ • \\ Paul Nieuwbeerta ${ }^{1}$
}

Received: 19 November 2018 / Revised: 24 September 2019 / Accepted: 17 March 2020 /

Published online: 8 April 2020

(C) The Author(s) 2020

\begin{abstract}
Given the large potential of prison-based treatment programs, it is highly important to empirically evaluate such programs in various populations in various geographic regions. The current study focused on the Dutch Prevention of Recidivism Program, a prison-based treatment program that aims to lower re-offending rates among participants by administering an individualized treatment program that addresses the criminogenic needs of an individual offender. It aimed to assess the extent to which the program was effective in reducing the post-release re-offending rates of program participants. This was studied by analyzing official prison data, risk assessment data, and re-offending records of a population-based sample of males incarcerated in The Netherlands. Proportional weighting within strata was applied to minimize selection effects. Study results showed that prisoners who completed a standard treatment program (which only consisted of phased re-entry), re-offended less in the 24 months post-release, compared to offenders in the control condition. This treatment effect was, however, not found when comparing prisoners who had completed a standard program plus cognitive skill training or substance abuse treatment, to those who had not. It was consequently concluded that participation in the prison-based Prevention of Recidivism program had a positive effect on post-release re-offending, for offenders who had engaged in a standard program that did not include any behavioral treatment modules. Results were discussed in light of theoretical and empirical considerations.
\end{abstract}

Keywords Prison · Treatment · Effectiveness · Propensity score methodology

Anouk Q. Bosma

a.q.bosma@law.leidenuniv.nl

Extended author information available on the last page of the article 


\section{Introduction}

When prisoners return to society, they often do so under far from optimal life circumstances. Many ex-detainees are unemployed, homeless, face financial difficulties, struggle with drug and/or alcohol addictions, and/or experience physical and psychiatric problems $[15,16,30,34,35,53,63,67,80$, 87]. Furthermore, studies have also indicated that prisons fail to turn offenders away from future criminal behavior (e.g., [28]).

Supported by a massive amount of empirical evidence showing the potential success of correctional treatment (see, e.g., [50]), several Western-initially particularly AngloAmerican - countries started to focus attention on better preparing detainees for life after prison. Consequently, prison-based rehabilitation programs aimed at lowering future criminal behavior and improving the circumstances of ex-detainees have been developed and implemented throughout the Western World [18, 36, 43, 59]. In The Netherlands, this has led to the nation-wide implementation of an integration approach to prison-based rehabilitation: The Prevention of Recidivism Program [83].

Correctional rehabilitation efforts can and should be, just as medical interventions, evidence based [47]. In the last decades, a large number of empirical studies have focused on examining factors that influence the effectiveness of correctional programs. A lot is, however, still unknown about the effectiveness of prison-based rehabilitation programs $[46,47]$. And while it is vital that we know which factors have influenced the effectiveness of correctional programs in past empirical studies, to help further the field of correctional rehabilitation research and practice, it is important that we continue to empirically evaluate rehabilitation programs in various populations in different geographic regions - especially since most research has been conducted in Canada, the US, and UK - and that we advance our understanding of the mechanisms through which effective interventions work [50]. The current study therefore aims to assess to what extent the national Dutch Prevention of Recidivism Program is effective in reducing the 6- and 24-month post-release re-offending rates of participating ex-detainees. To date, no such study has been conducted.

\section{Correctional Rehabilitation in The Netherlands}

Prison-based treatment efforts in The Netherlands are embedded within the Prevention of Recidivism Program. This is an intramural rehabilitation program, implemented in 2007, meant for detainees with a prison sentence of at least 4 months (i.e., remaining after being sentenced by a judge). ${ }^{1}$ The Prevention of Recidivism Program aims to lower re-offending rates among participants by offering the offender a chance to follow an individualized treatment program that addresses the specific criminogenic needs of the individual offender [25]. Participation in this program is voluntary. However, detainees who decide not to take part are not gradually placed in prison facilities with a lower security level (where they are granted more freedom) and have no ability to go

\footnotetext{
${ }^{1}$ Note that the program was replaced by a new policy measure that was implemented in March 2014, which uses the same risk/need based approach, but in which offenders can only take part if they have earned the right to engage, by expressing their willingness to change their criminal ways, and by showing pro-social behavior for a minimum of 6-weeks straight.
} 
on leave. They are also not eligible to spend up to one third of their sentence at home, under supervision of the Dutch Probation Organization. So, there is a strong incentive to participate.

Each year, around 5000 Dutch inmates meet the length-of-sentence criterion and are therefore eligible for participation in the program. This amounts to $11 \%$ of the total inflow of detainees in Dutch correctional institutions [7]. A computerized registration system automatically selects offenders after their sentence has been imposed based on their remaining prison sentence ( $>4$ months) and objective criteria (certain groups of detainees are excluded, such as offenders who are sentenced to prison for life, offenders who were placed in psychiatric facilities or penitentiary hospitals and illegal aliens). If an offender qualifies for program entry, subjective criteria (motivation and sufficient Dutch language skills) are verified and the offender is officially asked to participate in the program.

If an offender decides to participate, a risk assessment instrument is administered. This instrument is based on and highly comparable to the British Offender Assessment System (OASys) [39]. With this instrument, an offender's risk for recidivism is determined, and criminogenic needs are assessed concerning 12 specific subdomains: (1) offending history; (2) current offense and pattern of offenses; (3) accommodation; (4) education, work, and training; (5) financial management and income; (6) relationships with partner and relatives; (7) relationships with friends and other acquaintances; (8) drug misuse; (9) alcohol misuse; (10) emotional well-being; (11) thinking and behavior; and (12) attitudes/orientation [1]. Based on an offender's risk for recidivism and criminogenic needs, a customized rehabilitation program is formed (by a case manager), discussed with the offenders, and finally executed. This customized rehabilitation program can, if indicated by risk and need scores, contain specific treatment programs, the two most broadly applied are Cognitive Skills Training and Lifestyle Training. If need-specific treatment programs are, however, not indicated by risk assessment scores, prisoners can still enter the Prevention of Recidivism Program and are eligible for phased re-entry and early release without having to complete specific treatment modules (i.e., a standard program).

Cognitive Skills training is a Dutch version of Enhanced Thinking Skills (ETS) program [19]; a program that was developed for offenders who experience difficulties with the cognitive skills that are necessary to independently function in life and aims to improve cognitive skills that are necessary in order to independently live, develop, and function in society, by focusing on four key-objectives: impulse-control, perspective taking, problem solving, and moral insight. Cognitive skill training is offered as a standard version and a plus version, which was designed for offenders with limited mental capacities. The standard version consists of 22 group sessions for 10 to 12 participants. The plus version consists of 32 group meetings. The course was designed to target offenders with (at least) a moderate to high recidivism risk, who have shown impaired cognitive skills, and who were not excluded based on additional grounds, which are not being able to function in a group because of severe psychiatric problems, great difficulties in family functioning, and severe drug and or alcohol misuse [60].

Lifestyle training is an addiction treatment program designed to help offenders cope with alcohol, drug, and/or gambling addiction(s). The training relies on a cognitive behavioral approach, and focuses on motivation, self-control, and relapse prevention. There are two versions, a regular version that consists of 15 sessions, and a longer 
version meant for offenders with more severe addiction problems, consisting of 21 group meetings. The training aims to target offenders with drug, alcohol, and/or gambling abuse problems; not excluded on additional grounds, which are a negative attitude towards the sanction imposed; severe psychiatric problems; and being able to function in group treatment (SVG [84]). ${ }^{2}$

Depending on risk and need scores, some offenders may not qualify for any of these treatment programs. If this is the case, they can participate in the Prevention of Recidivism Program without allocation to any treatment module.

\section{Theoretical Framework}

The Prevention of Recidivism Program [PoR] is believed to lead to a reduction in recidivism rates in two ways (see also [8]). First, because prisoners who engage in the PoR program are eligible for phased re-entry and early release (standard program), and second, because effective treatment programs in line with an offenders risk and need profile are applied (standard program plus treatment).

Theoretically, gradually releasing offenders into society (earlier than the total duration of their sentence would originally imply) can minimize the potentially harmful effect of incarceration, can stimulate re integration, and may thereby reduce the odds for future re-offending. This assumption is based on the notion that imprisonment has a negative impact on offenders, with longer prison sentences leading to increased harm done. This negative effect of imprisonment can be explained by referring to the differential association tradition [77], which relies on the notion that criminal attitudes, values, and techniques are learned in association with deviant others, or the process of prisonization, in which imprisoned offenders learn the norms of an antisocial subculture during the time they remain incarcerated [20]. Others state that imprisonment is damaging because it removes offenders from society, which weakens interpersonal, familial, workplace, and economic bonds [62], thereby relating to a social bonds perspective of criminal behavior [37]. Finally, a long incarceration time can also prevent people from life-course transitions that according to Laub and Sampson [48] are related to a decrease in criminal behavior, such as getting and maintaining a relationship and/or employment. Based on each of these theoretical viewpoints, it is expected that a program that includes phased re-entry leads to reductions in post-release recidivism rates.

The effectiveness of risk and need-related treatment is usually explained by the RiskNeed-Responsivity [RNR-] model [5]. This model states that risk (who should be treated), need (what should be treated), and responsivity (how should it be treated) factors influence correctional rehabilitation outcomes. The RNR model is theoretically grounded by the General Personality and Cognitive Social Learning perspective of criminal behavior [3], which proclaims that criminal behavior represents a personality predisposition, which is learned in a social environment and is governed by the anticipated costs and actual rewards of offending behavior (for further reading, see: $[3,17,18]$ ). Criminogenic needs (factors that were shown related to future reoffending) are in essence characteristics that indicate rewards for criminal behavior,

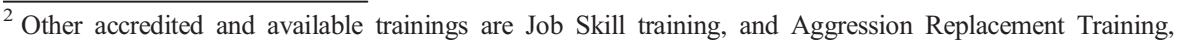
however, research has shown that these types of training are applied sparsely Anonymized (2013).
} 
as opposed to pro-social behavior [6]. In line with the General Personality and Cognitive Social Learning Perspective of Criminal Behavior, a correctional treatment program can be effective in reducing future re-offending if it is able to reduce or remove these criminogenic needs.

Although the overall effectiveness of treatment may be explained by the RNRmodel, other theories need to be marshaled to explain the effectiveness of the specific treatment modules applied (cognitive skill training and lifestyle training) within the PoR program. Cognitive skill training relies on a theoretical framework that is grounded in social learning theory $[13,70]$ and cognitive social learning theory [56]. In essence, these theories rely on the notion that, in interaction with environmental influences and opportunities for crime, a number of individual factors (or characteristics) is associated with persistent involvement in juvenile and adult criminal behavior. These factors include adherence to antisocial attitudes and beliefs, a pattern of deficits in (social-interactive) problem-solving, a lack in social perspective, and problems concerning self-management [3, 56, 71]. According to Ross and Fabiano [71], these different types of inadequacies in cognitive skills lead to behavioral tendencies that hinder an offender to function in a pro-social matter, with specific deficits leading to specific (criminal) tendencies.

First, adherence to anti-social attitudes and beliefs, which can manifest in deeply rooted beliefs with respect to antisocial behavior, the law and criminal justice system, can withhold offenders from reflecting on their own anti-social or criminal behavior. The inability to critically reflect on their own behavior can also cause offenders to often blame others for their own actions. Second, inadequacies in (social-interactive) problem solving may cause offenders to lack the ability to see that problems can develop (instead of just appear) and make it difficult for offenders to resolve problems and to visualize ways in which they can do so. Instead, offenders may accept situations, even if those situations involve great risks. Third, deficits relating to social perspectivetaking may cause delinquents to lack empathy, misinterpret social situations, be unaware of other human beings' feelings. Such deficits may furthermore increase the likelihood that offenders cannot differentiate between their own needs and needs of another person. And fourth, problems with respect to self-management may cause a tendency towards action-oriented behavior and impulsive behavior. Cognitive skill training was developed to target deficiencies or shortcomings with respect to these four problem areas. If cognitive deficits with respect to antisocial attitudes and beliefs, problem solving, social perspective, and self-management are improved, pro-criminal tendencies and behavior are expected to reduce. Therefore, it is expected that cognitive skill training will reduce post-release criminal behavior among offenders with cognitive-skill deficits.

Lifestyle training (treatment directed at addictive behavior) aims to decrease problematic substance abuse, which is believed to reduce the odds of future criminal behavior. Three types of models can be cited to describe the association between substance abuse and crime. The first perspective asserts that substance use leads to crime. This can be explained by referring to the psychopharmacological properties of drugs and alcohol, stating that intoxication (undermining judgment and self-control, causing paranoid thoughts or distorting inhibitions and perceptions) may lead to aggression (due to, for example, withdrawal or sleep deprivation; [85]) which in turn can cause criminal behavior $[21,26,90]$. It can also be clarified by referring to the 
economic motivation to get drugs or alcohol, in which drug and alcohol users are inevitably designated to non-legally acquired income to supply in their (often growing) demand (frequently referred to as pharmacological determinism, which asserts that people who were once exposed to drugs, often require this in increasing amounts; [2]). Lastly, it can be explained by a systemic model [32], which draws on the fact that substance abuse is fundamentally connected with violent crime.

The second perspective assumes that crime leads to substance abuse. This explanation claims that involvement in a criminal subculture provides the context, reference group and situations that increase the odds of coming into contact with drugs [89, 90]. Additionally, aspects of a professional criminal lifestyle may be linked to heavy drinking and drug use, because of the unstructured nature of criminal activity, the lack of ties (such as a marriage or children), and geographical mobility [22]. The third and final perspective to explain the link between substance abuse and criminal behavior refers to a model in which a relation is explained by a shared common cause, such as personality traits, antisocial personality disorder, parental drug and/or alcohol misuse, and poor relations with parents $[89,91]$, which cause both substance abuse and criminal conduct. As mentioned, lifestyle training aims to influence an offender's problematic addictive behavior, in order to reduce odds of future criminal re-offending. This mainly draws to the first theoretical perspective of substance abuse and criminal behavior, the assumption that substance abuse causes crime. Based on this model, it is expected that lifestyle training will reduce post-release criminal behavior among offenders with substance abuse problems.

\section{Previous Studies}

Literally, hundreds of studies have been conducted investigating the effects of a broad range of treatment modalities on recidivism among both juvenile and adult offenders in both residential and community settings. To combine the results of this enormous (and diverse) body of work and to identify patterns among study results, Lipsey and Cullen [50] conducted a systematic review of meta-analytic studies. This has shown that rehabilitative correctional interventions, on average, have shown positive (but small to moderate) results, while supervision and sanctioning have shown more moderate or-in some instances - negative (small to moderate) results. However, although previous work demonstrates the overall effectiveness of correctional treatment, it has also shown that there is great variety in correctional treatment programs and their effectiveness [50]. A more specific focus is therefore essential.

The PoR program is believed to lead to a reduction in recidivism rates by minimizing the time spent in (full-security) detention and by applying effective treatment programs in line with an offender's risk and need profile. Previous empirical studies have shown mixed results with respect to the hypothesized relationship between length of incarceration and post-release recidivism. Smith et al. [73] for example compared reoffending rates by length of incarceration and concluded that the time served in prison was positively related to the probability of re-offending. Similar results were also found in other studies (see for example $[12,33,68]$ ). However, other studies have found no significant relationship between length of stay and recidivism (see for example [52, 75]). 
The hypothesized relation between criminogenic need-specific treatment programs (in this case, cognitive skill training and lifestyle training) and post-release re-offending rates was also evidenced by previous scholarly work. Studies focusing on the effectiveness of cognitive skills programs in reducing the reoffending of ex-prisoners have found a significant treatment effect (see, e.g., [29, 44, 45, 51, 69, 72, 79]). For example, a review study conducted by Lipsey and others [51], in which studies were included that met standards 4 and 5 of the Maryland Scientific Methods Scale (i.e., an experimental or quasi-experimental design; [27]), revealed that recidivism rates for program participants were approximately four-fifth (so less) of that for control samples. In light of our theoretical framework, it was also shown that structured programmatic interventions that relied on principles derived from cognitive social learning theory [56] showed to achieve the largest and most consistent effect sizes in reducing criminal recidivism [31, 57].

Studies focusing on substance abuse treatment found similar results. A metaanalysis conducted by Irvin and others [41], which included studies on the effectiveness (in terms of substance abuse problems) of substance abuse programs that relied on the relapse prevention model [54], showed that relapse prevention was effective in increasing the psychosocial functioning of offenders and (although in lesser extent) was able to decrease substance abuse among program participants, especially with regards to those addicted to alcohol and poly drug addictions.

In conclusion, the results of previous studies conducted for the most part confirm the previously stated hypotheses. Previous work was, however, mainly conducted in Anglo-Saxon/common law countries. It must be empirically assessed if similar results are found in other geographic regions or countries, with perhaps a different legal, socioeconomical, and/or cultural context, such as The Netherlands.

\section{The Current Study}

The purpose of the current study was to examine the effectiveness of the Prevention of Recidivism Program: A national prison-based treatment program in The Netherlands that aims to lower re-offending rates among participants by administering an individualized treatment program that addresses the criminogenic needs of an individual offender. Entry in the PoR program also means that an offender is eligible for phased re-entry. A previously conducted literature review [7] revealed that no study evaluated the effectiveness of the PoR program. Therefore, based on the current state of empirical research, it is unknown if this program is effective in reducing post-release re-offending rates among participants. The following research question was therefore addressed: to what extent is the Prevention of Recidivism Program effective in reducing 6, and 24-month postrelease re-offending rates among program participants? This research question was studied by analyzing official prison data, risk assessment data, and re-offending records of a large population-based sample of males that were incarcerated in The Netherlands. To study re-offending among our research sample proportional weighting within strata was applied, to minimize concerns regarding selection effects that may have occurred and could perhaps not be properly accounted for by use of regression analyses. 


\section{Methods}

\section{Data}

To study the effect of rehabilitation efforts on incarcerated offenders in The Netherlands, a research sample was drawn from the Prison Project, a large scale, national population-based longitudinal research project, studying the effect of imprisonment on the life of detainees and their families in The Netherlands. The Prison Project included the total population of male detainees put in pre-trial detention in The Netherlands between October 2010 and March 2011. Additional inclusion criteria were that offenders had to be between the age of 18 and 65 and were born in The Netherlands. A number of 3.983 offenders met these qualifications and were included in the Prison Project [9, 10].

Several sources of information on the persons included in the sample were gathered to answer the research question proposed. First of all, the Dutch Custodial Institutions Agency provided registration data from several prison registration systems on all persons in the sample, including data on background characteristics (Prison Registration System), in-depth information regarding rehabilitation trajectories (Prevention of Recidivism Registration System), and incarceration details such as in and outflow, transfers between prisons, departments, and cells (Prison Registration System). Second, risk assessment data on the persons in the sample were made available by the Dutch Probation Service. Third, the Research and Documentation Centre of the Dutch Ministry of Security and Justice provided data from the General Documentation Files (GDF) of the Criminal Record Office. These data contain detailed information on all registered crimes and convictions up to December 2015, and provide information about the offender's criminal history, current offense and registered re-offending behavior 6 months after release. Finally, information on sentencing outcomes was made available by the Dutch Prosecution Office. This data contained sentencing outcomes on each detainee's criminal case.

As mentioned, 3.981 offenders were part of the original Prison Project research sample. Because recidivism is studied over a (maximum of) 24-month follow-up period, and recidivism data were only available until the end of December 2015, only those detainees were included in the current study that had left prison before the end of December 2013. This way, each offender has been released from prison for at least 24 months. Consequently, 145 offenders were excluded from the sample. Additionally, one offender was excluded from the sample because data from the GDF of the Criminal Record Office was missing, which meant no criminal record information was available. By removing these offenders, 3.835 offenders formed the current study's sample.

\section{Variables}

\section{Dependent Variables}

The dependent variable used in the current study was registered criminal re-offending within 6 and within 24 months after release. A 6-month period after release was chosen because research has indicated that the first months following release are characterized by a high risk for re-offending (e.g., [86]), and difficulties with respect to community 
re-integration (e.g., [14]). To offer a more long-term view, 2-year recidivism was also included. Recidivism was measured by including charges that were drawn from the General Documentation Files. All criminal charges were included except for those that ended in acquittal or were dismissed. This resulted in two dichotomously coded variables $(0=$ not charged within $6 / 24$ months post-release, $1=$ charged within $6 / 24$ months post-release).

\section{Independent Variable: Treatment Group}

Treatment groups were based on data retrieved from the official Prevention of Recidivism Registration System. This administrative database, which is accessible and used in every prison in The Netherlands, provides in-depth information on all activities (including program status) regarding the PoR program. Information regarding an offender's status could therefore easily be retrieved, without having to interpret or recode variables. The registration system also provides information regarding reasons for non-participation and non-completion. By consulting this database, our entire research group could be divided into nine treatment groups: (1) program noncandidates (those who did not qualify for program participation); (2) program nonparticipants: organizational reasons (those who could not take part for organizational reasons, such as staff shortages); (3) program non-participants: refused (those who refused to take part); (4) program completers: standard treatment program (those who completed treatment without having been engaged in a need-specific treatment program); (5) program completers: standard program plus cognitive skill training; (6) program completers: standard program plus lifestyle training; (7) program completers: standard program plus cognitive skill and lifestyle training; (8) non-completers: organizational reasons (those who started, but did not complete for organizational reasons, such as staff shortages); and (9) non-completers: own choice (those who started treatment, but had dropped out at their own request; see Fig. 1).

\section{Covariates}

In studying the impact of treatment on post-release re-offending rates, it is important to take into account other factors that could have potentially also influenced treatment, as well as post-release recidivism. Fortunately, the various registration files that were available made it possible to include a wide range of covariates in our analyses. We incorporated a long list of variables that may have influenced treatment group membership and/or re-offending behavior, which were grouped under demographics, criminal history, current offense, and risk assessment.

Demographics accounted for in the current study included age and ethnic background. Age (in years) was calculated from the prison registration systems by subtracting date of birth from the date of their prison entry. Ethnic background (nonnative vs. native; Statistics Netherlands defines a person as having a non-native background if at least one of his/her parents was born abroad) was obtained from municipal data, and if not available, was subtracted from risk assessment data.

Several variables related to criminal history were also included in the analyses, namely the age of onset; number of prior convictions for a violent crime (ever and in the last 5 years); number of prior convictions for a property crime (ever and in the last 


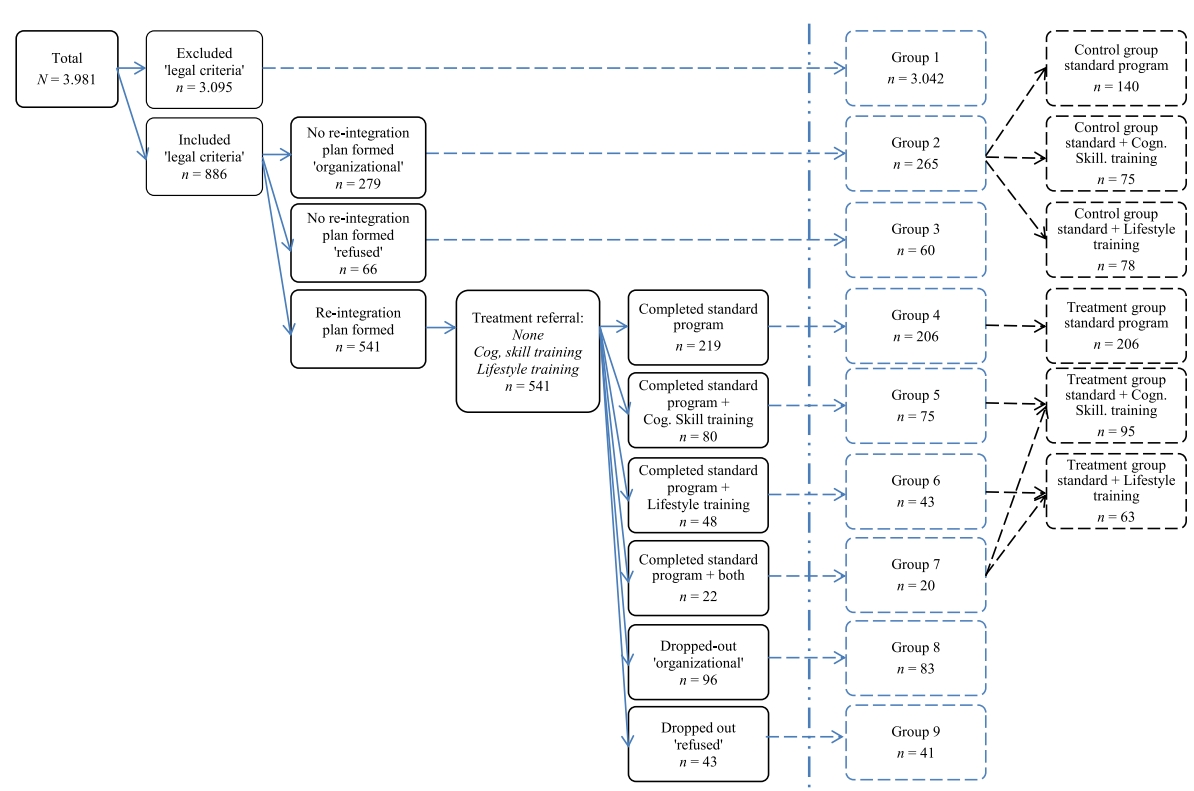

Outflow before 31.12 .2013

Fig. 1 Research sample, divided in treatment groups

5 years); number of prior convictions for other crimes (ever and in the last 5 years); and number of previous prison sentences (ever and in the last 5 years). All criminal history variables were extracted from General Documentation Files (GDF) of the Criminal Record Office.

To control for the influence of an offender's current offense, the type of offense (violent, sex, violent property, property, damage, drug related or other/unknown) and total imposed sentence (duration, not including a conditional sentence) was included. Offense type was drawn from the General Documentation Files (GDF) of the Criminal Record Office and imposed sentence length was drawn from data provided by the Dutch prosecution office.

Finally, a variable used to indicate an offender's risk for future re-offending was also incorporated. In Dutch corrections, criminogenic risk and needs are determined using the Dutch-language Recidivism Assessment Scales (RISc). This instrument, which is based on the British Offender Assessment System (OASys) [39], screens offenders on 12 risk domains: (1) offending history and (2) current offense and pattern of offenses; (3) accommodation; (4) education, work, and training; (5) financial management and income; (6) relationships with partner, family, and relatives; (7) relationships with friends and acquaintances; (8) drug misuse; (9) alcohol misuse; (10) emotional wellbeing; (11) thinking and behavior; and (12) attitudes and orientation. Most RISc items are scaled 0 (no problems), 1 (some problems), or 2 (significant problems). The overall risk for future re-offending is determined by grouping weighted domain scores into four levels: (1) low risk, (2) low to medium risk, (3) medium to high risk, and (4) high risk [82]. Studies have indicated that the reliability and internal consistency, as well as the predictive validity of the RISc, are adequate (see [81]). For the purpose of this study, risk indications were dichotomized into low to medium/low risk (coded 0) and 
medium/high to high risk (coded 1). Descriptive statistics of the variables included in this study, per treatment group, are presented in Table 1.

\section{Analyses}

In order to study the effectiveness of the PoR program offenders that completed treatment were compared to a group of offenders that did not. A simple comparison between post-prison re-offending rates of the treatment group with the control groups would, however, not be sufficient, because treatment group membership may be confounded with factors that affect both treatment inclusion, but also influence postrelease re-offending. Also, selection effects that may have occurred could perhaps not be properly accounted for by use of regression analyses. The current study therefore assessed the effectiveness of treatment by applying proportional weighting within strata (see [66], for a similar approach), to eliminate the influence of measurable pretreatment covariates that may have otherwise influenced results [11, 65]. By obtaining balance between groups in covariates, any differences in post-imprisonment reoffending outcomes can be assumed to be the result of a treatment effect [92]. This method will be described in detail below.

\section{Treatment and Control Condition Selection}

First, a group of offenders was identified that had successfully completed the PoR program (the treatment group, consisting of offenders that had completed a standard program, or a standard program with cognitive skill training, lifestyle training or both), which consisted of 344 offenders (see Fig. 1; treatment groups 4, 5, 6 and 7). These offenders were, based on their remaining prison sentence at the moment of conviction (>4 months), selected as a program candidate, had decided to participate, and had completed an individualized treatment program that had addressed their specific criminogenic needs.

In light of the current study, the treatment group was compared to an appropriate control group. In several previous quasi-experimental (treatment) effect studies, a control group of offenders was created by selecting offenders who decided not to participate (see, e.g., [55, 93]) or dropped-out during treatment (see, e.g., [88]). This, however, is not an optimal control condition, since previous studies have shown that offenders who do not engage in or complete treatment can generally be seen as a highrisk group of offenders $[64,94]$. Selecting these potentially high-risk offenders as a control group may therefore lead to over-estimating treatment effects [58, 64, 94]. We therefore selected a control group consisting of offenders that were, based on the program's inclusion criteria (the most important of which being a remaining sentence length of at least 4 months at the moment of conviction), assigned a candidate for the program, but could not participate due to organizational reasons (for example caused by a lack in available treatment places, or staff shortages). This was determined based on information included in the official Prevention of Recidivism Registration System. This control group consisted of 265 offenders (see Fig. 1; treatment group 2).

Offenders in our treatment condition each completed a different treatment program (i.e., a standard program, a standard program plus cognitive skill training, a standard program plus lifestyle training, and a standard program plus both), this provided a 


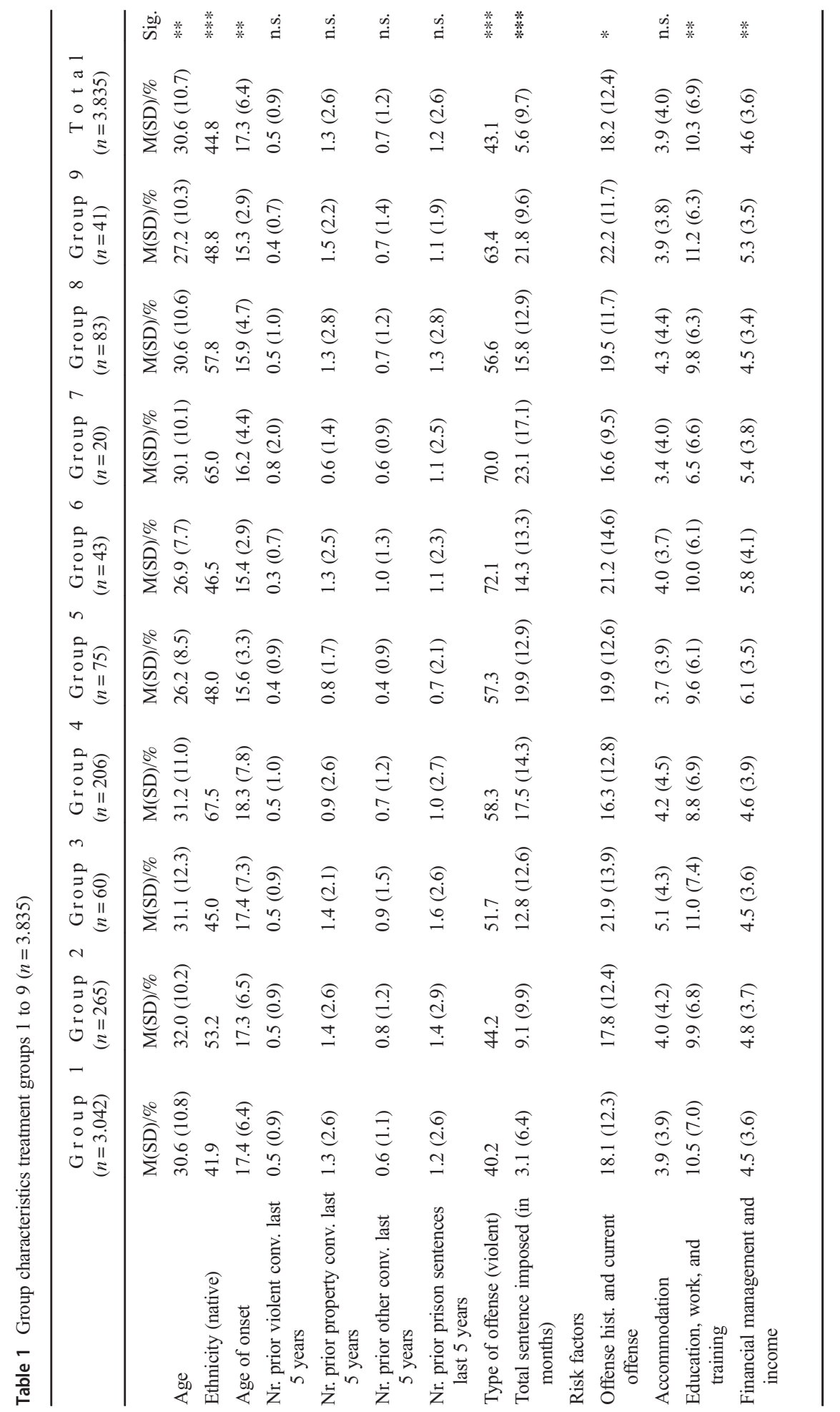




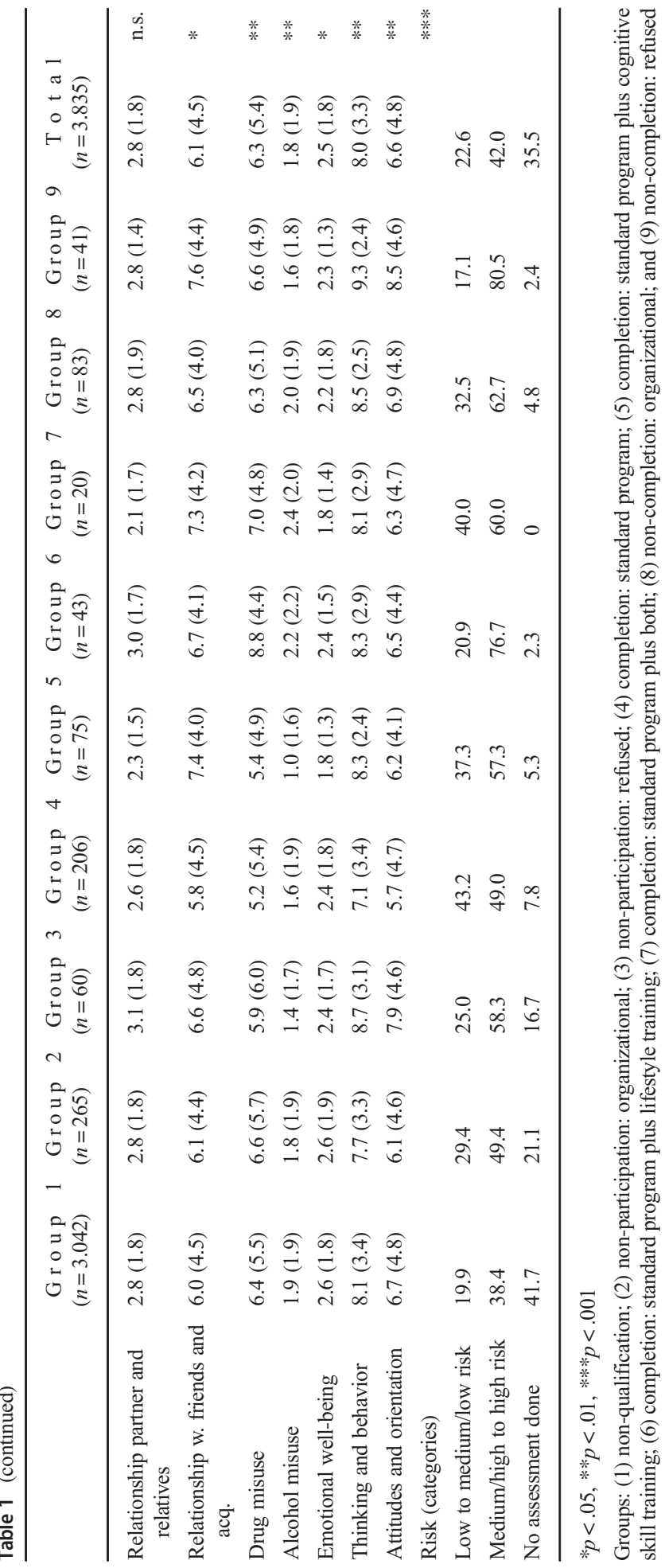


perfect opportunity to not only assess the effectiveness of the PoR program, but to also address if program effectiveness differed among groups of offenders that completed different types of treatment. Accordingly, three treatment groups were formed: (1) offenders that completed a standard program $(n=206)$, (2) offenders that completed a standard program plus cognitive skill training $(n=95)$, and (3) offenders that completed a standard program plus lifestyle training $(n=63)$. Offenders that completed both $(n=20)$ represent such a minor treatment group that statistical analyses would prove to be difficult. Therefore, these offenders were added to both the cognitive skill training treatment group and the lifestyle training treatment group. This does, however, imply that both treatment groups in part consist of a relatively small group of offenders that have problems in more than one area. Since it cannot be ruled out that the control group also has prisoners with problems concerning both need types, we did not consider this a major issue and did not expect this to influence results.

These groups were each compared to an appropriate control group of offenders, for whom potential treatment module candidacy was determined based on their risk for recidivism and criminogenic needs (in line with the inclusion criteria for cognitive skill and lifestyle training, described in this chapter). This resulted in three control conditions: (1) offenders that qualified for a standard program $(n=140),(2)$ offenders that qualified for a standard program plus cognitive skill training $(n=75)$, and (3) offenders that qualified for a standard program plus lifestyle training $(n=63)$. Again, offenders that qualified to take part in both $(n=28)$ represented such a minor control group that statistical analyses would not be possible. Therefore, these offenders were added to both the cognitive skill training control group, as well as the lifestyle training control group. Descriptive statistics on each of the control and treatment groups can be viewed in Tables 2, 3, and 4 .

\section{Proportional Weighting Analysis}

The first step in our proportional weighting strategy involved an assessment of group differences on background characteristics. Tables 2, 3, and show the results of an un-weighted comparison on variable means that were included in the current study, for our treatment and control group referred to (or qualified for) a standard program, a standard program plus cognitive skill training, and a standard program plus lifestyle training. Group differences between the treatment and control group were statistically tested for significance using appropriate techniques (Chi-square, $t$ test, and ANOVA).

As shown in Table 2, the treatment group and control group (standard program) differed significantly regarding their age, ethnicity, the number of prior property convictions in their criminal history, offense type (violent), their risk for re-offending, and the total prison sentence imposed. Regarding group differences between our second treatment group and control group (standard program plus cognitive skill training), results, which are presented in Table 3, show that these groups are already highly similar. They do, however, differ with respect to offense type (property), and prison sentence imposed. Table 4 shows a final comparison, made between the current study's third treatment group and control group (standard program plus lifestyle training), which showed that group differences were reported with respect to age, the number 
Table 2 Un-weighted and weighted means treatment group $(n=206)$ vs. control group $(n=140)$, standard program

\begin{tabular}{|c|c|c|c|c|c|}
\hline & \multirow{3}{*}{$\begin{array}{l}\text { Treatment group } \\
\mathrm{M}(S D)\end{array}$} & \multirow{2}{*}{\multicolumn{2}{|c|}{$\begin{array}{l}\text { Un-weighted means } \\
\text { Control group }\end{array}$}} & \multirow{2}{*}{\multicolumn{2}{|c|}{$\begin{array}{l}\text { Weighted means } \\
\text { Control group }\end{array}$}} \\
\hline & & & & & \\
\hline & & $\mathrm{M}(S D)$ & $p$ & $\mathrm{M}(S D)$ & $p$ \\
\hline \multicolumn{6}{|l|}{ Covariate: demographics } \\
\hline Age (in years) & $31.2(11.0)$ & $34.1(10.2)$ & $.016^{*}$ & $32.2(9.8)$ & .402 \\
\hline \multicolumn{6}{|l|}{ Ethnicity } \\
\hline Native & $0.7(0.5)$ & $0.5(0.5)$ & $.002 * *$ & $0.7(0.5)$ & .997 \\
\hline Non-native & $0.3(0.5)$ & $0.2(0.4)$ & .296 & $0.3(0.5)$ & .874 \\
\hline Unknown & $0.0(0.2)$ & $0.3(0.4)$ & $.000 * * *$ & $0.0(0.2)$ & .729 \\
\hline \multicolumn{6}{|l|}{ Covariate: criminal history } \\
\hline Age of onset & $18.3(7.8)$ & $18.5(7.3)$ & .872 & $19.2(8.7)$ & .350 \\
\hline Nr. prior violent conv. last 5 years & $0.5(1.0)$ & $0.6(1.0)$ & .181 & $0.5(0.9)$ & .786 \\
\hline Nr. prior property conv. last 5 years & $0.9(2.6)$ & $1.6(3.0)$ & $.034 *$ & $1.0(2.2)$ & .683 \\
\hline Nr. prior other conv. last 5 years & $0.7(1.2)$ & $0.9(1.3)$ & .086 & $0.7(1.1)$ & .776 \\
\hline Nr. prior prison sentences last 5 years & $1.0(2.7)$ & $1.6(3.3)$ & .078 & $1.0(2.3)$ & .914 \\
\hline Nr. prior violent conv. ever & $1.0(1.9)$ & $1.4(2.0)$ & .071 & $0.9(1.7)$ & .785 \\
\hline Nr. prior property conv. ever & $2.8(6.9)$ & $4.3(6.7)$ & .057 & $3.0(5.6)$ & .841 \\
\hline Nr. prior other conv. Ever & $1.8(3.6)$ & $2.5(3.5)$ & .065 & $1.7(2.7)$ & .835 \\
\hline Nr. prior prison sentences ever & $2.3(6.3)$ & $3.3(6.1)$ & .149 & $2.3(4.7)$ & .949 \\
\hline \multicolumn{6}{|l|}{ Covariate: Current offense } \\
\hline \multicolumn{6}{|l|}{ Offense type } \\
\hline Violent & $0.6(0.5)$ & $0.4(0.5)$ & $.007 *$ & $0.6(0.5)$ & .405 \\
\hline Property & $0.2(0.5)$ & $0.2(0.4)$ & .114 & $0.2(0.4)$ & .996 \\
\hline Damage & $0.0(0.1)$ & $0.0(0.2)$ & .203 & $0.0(0.1)$ & .873 \\
\hline Drug-related & $0.0(0.2)$ & $0.0(0.2)$ & .931 & $0.0(0.2)$ & .917 \\
\hline Other & $0.0(0.1)$ & $0.0(0.0)$ & .411 & $0.0(0.0)$ & .423 \\
\hline \multicolumn{6}{|l|}{ Covariate: risk assessment (categorical) } \\
\hline Low to medium/low risk & $0.4(0.5)$ & $0.2(0.4)$ & $.000 * * *$ & $0.4(0.5)$ & .515 \\
\hline Medium/high to high risk & $0.5(0.5)$ & $0.4(0.5)$ & $.000 * * *$ & $0.5(0.5)$ & .893 \\
\hline No assessment done & $0.1(0.3)$ & $0.4(0.5)$ & $.020 *$ & $0.1(0.3)$ & .817 \\
\hline \multicolumn{6}{|l|}{ Sentence length } \\
\hline Total sentence imposed (in months) & $17.5(14.3)$ & $9.4(10.6)$ & $.000 * * *$ & - & - \\
\hline \multicolumn{6}{|l|}{ Propensity score } \\
\hline Predicted probability (tr. group membership) & $0.69(0.16)$ & $0.46(0.26)$ & $.000 * * *$ & $0.67(0.16)$ & .442 \\
\hline
\end{tabular}

of prior property convictions in their criminal history, type of offense (violent and property), and total prison sentence imposed.

In conclusion, the characteristics on the un-weighted data presented in Tables 2, 3, and 4 indicate that there are group differences between our three treatment conditions and control conditions. In order to be able to compare the re-offending rates of 
Table 3 Un-weighted and weighted means treatment group $(n=95)$ vs. control group $(n=75)$, standard program plus cognitive skill training

\begin{tabular}{|c|c|c|c|c|c|}
\hline & \multirow{3}{*}{$\begin{array}{l}\text { Treatment group } \\
\mathrm{M}(S D)\end{array}$} & \multirow{2}{*}{\multicolumn{2}{|c|}{$\begin{array}{l}\text { Un-weighted means } \\
\text { Control group }\end{array}$}} & \multirow{2}{*}{\multicolumn{2}{|c|}{$\begin{array}{l}\text { Weighted means } \\
\text { Control group }\end{array}$}} \\
\hline & & & & & \\
\hline & & $\mathrm{M}(S D)$ & $p$ & $\mathrm{M}(S D)$ & $p$ \\
\hline \multicolumn{6}{|l|}{ Covariate: demographics } \\
\hline Age (in years) & $27.0(8.9)$ & $27.5(9.1)$ & .762 & $27.4(10.2)$ & .780 \\
\hline \multicolumn{6}{|l|}{ Ethnicity } \\
\hline Native & $0.5(0.5)$ & $0.5(0.5)$ & .907 & $0.5(0.5)$ & .436 \\
\hline Non-native & $0.5(0.5)$ & $0.5(0.5)$ & .899 & $0.5(0.5)$ & .409 \\
\hline Unknown & $0.0(0.2)$ & $0.1(0.1)$ & .471 & $0.0(0.1)$ & .865 \\
\hline \multicolumn{6}{|l|}{ Covariate: criminal history } \\
\hline Age of onset & $15.7(3.6)$ & $15.5(3.4)$ & .594 & $15.3(3.3)$ & .437 \\
\hline Nr. prior violent conv. last 5 years & $0.5(1.2)$ & $0.4(0.7)$ & .832 & $0.4(0.7)$ & .552 \\
\hline Nr. prior property conv. last 5 years & $0.7(1.7)$ & $0.7(1.5)$ & .969 & $1.3(2.5)$ & .113 \\
\hline Nr. prior other conv. last 5 years & $0.5(0.9)$ & $0.6(1.2)$ & .482 & $0.3(0.8)$ & .385 \\
\hline Nr. prior prison sentences last 5 years & $0.8(2.2)$ & $0.8(1.9)$ & .960 & $1.2(2.5)$ & .317 \\
\hline Nr. prior violent conv. ever & $0.9(2.2)$ & $0.9(1.8)$ & .862 & $0.7(1.3)$ & .525 \\
\hline Nr. prior property conv. ever & $2.4(6.5)$ & $3.0(6.6)$ & .532 & $2.9(5.3)$ & .599 \\
\hline Nr. prior other conv. ever & $1.2(2.2)$ & $1.5(2.6)$ & .445 & $0.9(1.7)$ & .401 \\
\hline Nr. prior prison sentences ever & $1.9(5.6)$ & $2.1(4.7)$ & .763 & $2.1(4.0)$ & .713 \\
\hline \multicolumn{6}{|l|}{ Covariate: current offense } \\
\hline \multicolumn{6}{|l|}{ Offense type } \\
\hline Violent & $0.6(0.5)$ & $0.5(0.5)$ & .226 & $0.7(0.5)$ & .181 \\
\hline Property & $0.2(0.4)$ & $0.3(0.5)$ & $.007 * *$ & $0.1(0.3)$ & .550 \\
\hline Damage & $0.0(0.2)$ & $0.0(0.2)$ & .852 & $0.0(0.1)$ & .679 \\
\hline Drug-related & $0.0(0.1)$ & $0.0(0.2)$ & .812 & $0.0(0.1)$ & .810 \\
\hline Other & $0.0(0.0)$ & $0.0(0.0)$ & - & $0.0(0.0)$ & - \\
\hline \multicolumn{6}{|l|}{ Covariate: risk assessment (categorical) } \\
\hline Low to medium/low risk & $0.4(0.5)$ & $0.4(0.5)$ & .801 & $0.4(0.5)$ & .782 \\
\hline Medium/high to high risk & $0.6(0.5)$ & $0.6(0.5)$ & .422 & $0.6(0.5)$ & .409 \\
\hline \multicolumn{6}{|l|}{ Sentence length } \\
\hline Total sentence imposed (in months) & $20.5(13.8)$ & $9.9(10.3)$ & $.000 * * *$ & - & - \\
\hline \multicolumn{6}{|l|}{ Propensity score } \\
\hline Predicted probability (tr. group membership) & $0.60(0.14)$ & $0.51(0.15)$ & $.000 * * *$ & $0.60(0.14)$ & .844 \\
\hline
\end{tabular}

offenders that received one of three types of programs, with offenders in our control condition, balance needed to be created on covariates. This procedure involved several steps. The first step was to generate predicted probabilities of treatment versus control group membership by applying a logistic regression analysis, the results of which are presented in Table 5. Because group differences regarding sentence length were 
Table 4 Un-weighted and weighted means treatment group $(n=63)$ vs. control group $(n=78)$, standard program plus lifestyle training

\begin{tabular}{|c|c|c|c|c|c|}
\hline & \multirow{3}{*}{$\begin{array}{l}\text { Treatment group } \\
\mathrm{M}(S D)\end{array}$} & \multirow{2}{*}{\multicolumn{2}{|c|}{$\begin{array}{l}\text { Un-weighted means } \\
\text { Control group }\end{array}$}} & \multirow{2}{*}{\multicolumn{2}{|c|}{$\begin{array}{l}\text { Weighted means } \\
\text { Control group }\end{array}$}} \\
\hline & & & & & \\
\hline & & $\mathrm{M}(S D)$ & $p$ & $\mathrm{M}(S D)$ & $p$ \\
\hline \multicolumn{6}{|l|}{ Covariate: demographics } \\
\hline Age (in years) & $27.9(8.6)$ & $31.5(9.8)$ & $.026^{*}$ & $27.8(8.8)$ & .937 \\
\hline \multicolumn{6}{|l|}{ Ethnicity } \\
\hline Native & $0.5(0.5)$ & $0.6(0.5)$ & .747 & $0.5(0.5)$ & .620 \\
\hline Non-native & $0.4(0.5)$ & $0.4(0.5)$ & .624 & $0.5(0.5)$ & .467 \\
\hline Unknown & $0.1(0.2)$ & $0.1(0.3)$ & .759 & $0.0(0.2)$ & .611 \\
\hline \multicolumn{6}{|l|}{ Covariate: criminal history } \\
\hline Age of onset & $15.6(3.4)$ & $16.4(5.8)$ & .363 & $15.2(5.0)$ & .537 \\
\hline Nr. prior violent conv. last 5 years & $0.5(1.3)$ & $0.5(0.8)$ & .950 & $0.3(0.6)$ & .313 \\
\hline Nr. prior property conv. last 5 years & $1.1(2.3)$ & $1.4(2.2)$ & .349 & $1.0(1.8)$ & .774 \\
\hline Nr. prior other conv. last 5 years & $0.9(1.2)$ & $0.7(1.1)$ & .331 & $0.8(1.3)$ & .845 \\
\hline Nr. prior prison sentences last 5 years & $1.1(2.4)$ & $1.6(2.7)$ & .261 & $1.0(2.2)$ & .831 \\
\hline Nr. prior violent conv. ever & $1.1(2.5)$ & $1.3(1.9)$ & .583 & $0.8(1.5)$ & .378 \\
\hline Nr. prior property conv. ever & $2.6(5.1)$ & $4.8(7.4)$ & $.043 *$ & $2.6(5.0)$ & .997 \\
\hline Nr. prior other conv. Ever & $1.9(3.2)$ & $1.9(2.8)$ & .984 & $2.0(2.7)$ & .946 \\
\hline Nr. prior prison sentences ever & $2.2(5.4)$ & $3.7(5.9)$ & .113 & $2.0(4.6)$ & .856 \\
\hline \multicolumn{6}{|l|}{ Covariate: current offense } \\
\hline \multicolumn{6}{|l|}{ Offense type } \\
\hline Violent & $0.7(0.5)$ & $0.4(0.5)$ & $.000 * * *$ & $0.7(0.5)$ & .467 \\
\hline Property & $0.2(0.4)$ & $0.4(0.5)$ & $.001 * *$ & $0.2(0.4)$ & .285 \\
\hline Damage & $0.0(0.2)$ & $0.0(0.2)$ & .830 & $0.0(0.2)$ & .759 \\
\hline Drug-related & $0.0(0.1)$ & $0.0(0.1)$ & .880 & $0.0(0.2)$ & .528 \\
\hline Other & $0.0(0.0)$ & $0.0(0.0)$ & - & $0.0(0.1)$ & .287 \\
\hline \multicolumn{6}{|l|}{ Covariate: risk assessment (categorical) } \\
\hline Low to medium/low risk & $0.3(0.4)$ & $0.4(0.5)$ & .334 & $0.3(0.5)$ & .800 \\
\hline Medium/high to high risk & $0.7(0.5)$ & $0.7(0.5)$ & .448 & $0.7(0.5)$ & .960 \\
\hline \multicolumn{6}{|l|}{ Sentence length } \\
\hline Total sentence imposed (in months) & $17.1(15.1)$ & $8.2(10.2)$ & $.000 * * *$ & - & - \\
\hline \multicolumn{6}{|l|}{ Propensity score } \\
\hline Predicted probability (tr. group membership) & $0.55(0.19)$ & $0.36(0.20)$ & $.000 * * *$ & $0.52(0.18)$ & .341 \\
\hline
\end{tabular}

relatively large, this variable was not included in the propensity score model, but was controlled for in a multiple logistic regression analyses.

A second step (consecutively executed for treatment and control groups 1, 2, and 3) involved sorting data into strata, based on each subjects so-called propensity score (i.e., the predicted probability obtained from the logistic regression analyses in step 1). In 
Table 5 Estimated parameters of treatment group membership vs. control group membership, standard program, standard program plus cognitive skill training, and standard program plus lifestyle training

\begin{tabular}{|c|c|c|c|c|c|c|}
\hline & \multicolumn{2}{|c|}{$\begin{array}{l}\text { Treatment }(n=206) \\
\text { vs. control group } \\
(n=140), \text { standard } \\
\text { program }\end{array}$} & \multicolumn{2}{|c|}{$\begin{array}{l}\text { Treatment }(n=95) \text { vs. } \\
\text { control group }(n=75), \\
\text { standard program plus } \\
\text { cognitive skill training }\end{array}$} & \multicolumn{2}{|c|}{$\begin{array}{l}\text { Treatment }(n=63) \text { vs. } \\
\text { control group }(n=78) \\
\text { standard program plus } \\
\text { lifestyle training }\end{array}$} \\
\hline & OR & Sig. & OR & Sig. & OR & Sig. \\
\hline \multicolumn{7}{|l|}{ Covariate: demographics } \\
\hline Age (in years) & 0.98 & n.s. & 0.99 & n.s. & 0.95 & n.s. \\
\hline \multicolumn{7}{|l|}{ Ethnicity } \\
\hline Native & ref & ref & ref & $r e f$ & ref & ref \\
\hline Non-native & 4.41 & $* *$ & 2.05 & n.s. & 1.20 & n.s. \\
\hline Unknown & 3.63 & $*$ & 1.54 & n.s. & 0.96 & n.s. \\
\hline \multicolumn{7}{|l|}{ Covariate: criminal history } \\
\hline Age of onset & 1.00 & n.s. & 1.01 & n.s. & 1.00 & n.s. \\
\hline $\begin{array}{l}\text { Nr. prior violent conv. last } \\
5 \text { years }\end{array}$ & 0.93 & n.s. & 1.26 & n.s. & 1.53 & n.s. \\
\hline $\begin{array}{l}\text { Nr. prior property conv. last } \\
5 \text { years }\end{array}$ & 0.76 & n.s. & 1.31 & n.s. & 1.26 & n.s. \\
\hline $\begin{array}{l}\text { Nr. prior other conv. last } \\
5 \text { years }\end{array}$ & 0.87 & n.s. & 0.98 & n.s. & 1.33 & n.s. \\
\hline $\begin{array}{l}\text { Nr. prior prison sentences last } \\
5 \text { years }\end{array}$ & 1.19 & n.s. & 0.83 & n.s. & 0.80 & n.s. \\
\hline Nr. prior violent conv. Ever & 0.86 & n.s. & 0.90 & n.s. & 0.86 & n.s. \\
\hline Nr. prior property conv. Ever & 1.04 & n.s. & 0.91 & n.s. & 0.94 & n.s. \\
\hline Nr. prior other conv. Ever & 0.98 & n.s. & 0.94 & n.s. & 1.16 & n.s. \\
\hline $\begin{array}{l}\text { Nr. prior prison sentences } \\
\text { ever }\end{array}$ & 1.08 & n.s. & 1.16 & n.s. & 1.04 & n.s. \\
\hline \multicolumn{7}{|l|}{ Covariate: current offense } \\
\hline \multicolumn{7}{|l|}{ Offense type } \\
\hline Violent & ref & ref & ref & ref & ref & ref \\
\hline Property & 0.60 & n.s. & 0.40 & $*$ & 0.18 & $* *$ \\
\hline Damage & 0.43 & n.s. & 1.05 & n.s. & 0.61 & n.s. \\
\hline Drug-related & 0.81 & n.s. & 3.85 & $*$ & 0.77 & n.s. \\
\hline Other & 0.61 & n.s. & 0.38 & n.s. & 0.16 & n.s. \\
\hline \multicolumn{7}{|l|}{ Covariate: risk assessment } \\
\hline \multicolumn{7}{|l|}{ Risk } \\
\hline Low to medium/low risk & ref & ref & ref & ref & ref & ref \\
\hline Medium/high to high risk & 6.33 & $* * *$ & 1.12 & n.s. & 1.52 & n.s. \\
\hline No assessment done & 0.98 & $* * *$ & - & - & - & - \\
\hline
\end{tabular}

Note: $* p \leq .05, * * p \leq .01, * * * p \leq .001$

order to be as precise as possible, in relation to our relatively modest sample size, 20 strata ( 0 to $0.05,0.06$ to $0.10,0.11$ to 0.15 , and so forth) were distinguished. The number of observations within each group was then calculated and a weight was 
assigned to each observation within each group (the weight within each stratum is equal to the proportion of observations in that stratum group [treatment or control group] relative to the total number of observations in that stratum; see [11, 65]). The final step was to rescale the weights so that the sum of all weights within each treatment group was equal to the total sample size of each treatment group.

After applying this technique, weighted means of the characteristics were calculated (also presented in Tables 2, 3, and 4) to once again compare the three treatment and control groups on each propensity score variable, and to assess if balance was created using the proportional weighting technique. A group comparison on weighted means between our first treatment group and control condition (standard program) shows that balance on all covariates was created. There were no weighted group differences reported on any of the included pre-treatment covariates, indicating an appropriate control condition with minimal (observable) confounding of covariates that may have influenced results. Concerning the group comparison between our second treatment group (standard program plus cognitive skill training) and control condition balance on all covariates was also created. Again, this control group seemed appropriate, with no (observable) confounding of covariates. Finally, with respect to a group comparison between our third treatment group (standard program plus lifestyle training) and control condition, it was also shown that no weighted group differences were reported on any of our pre-treatment covariates included. This again indicated an appropriate control condition, with no (observable) confounding of covariates.

By use of our weighting technique, the current study was able to account for a large number of covariates that may have influenced both treatment group membership as well as post-release re-offending outcomes. In order to properly account for sentence length, a set of logistic regression analyses were performed in which sentence length in months was included and controlled for.

\section{Results}

Based on proportional weighting within strata, a group of program completers referred to a standard program was compared to a control group of offenders who had been eligible for a standard treatment program, but who could not participate for organizational reasons. Second, a group of program completers referred to a standard program plus cognitive skill training was compared to a control group of offenders who had been eligible for a standard treatment program plus cognitive skill training, but who could not participate for organizational reasons. And third, a group of program completers referred to a standard program plus lifestyle training was compared to a control group of offenders who had been eligible for a standard treatment program plus lifestyle training, but who could not participate for organizational reasons. After our weighting procedure (described in great detail in the method section), a Chi-square test is used to assess if there was an un-weighted and weighted effect of treatment group membership on 6- and 24month post-release re-offending rates for each of our three groups defined, the results of which are presented below. 


\section{The Impact of a Standard Treatment Program}

First (as shown in Table 6) an un-weighted comparison of 6- and 24-month post-release re-offending rates of offenders in the treatment group that completed a standard program, and control condition (offenders who were eligible for treatment but were excluded for organizational reasons) indicated that offenders in the treatment group were not less often re-charged in the 6-month post-imprisonment compared to those in the control condition, since no significant treatment $(-7.8 \%)$ effect was found. They were, however, less likely to have been re-charged 24-month post-imprisonment ($10.4 \%$ ). Next, a weighted comparison between the treatment and control group (standard program) was conducted, which revealed that offenders in the control condition were re-charged significantly more often 6- and 24-month post-imprisonment $(27.8 \%$ and $52.7 \%$ ), compared to offenders that had received treatment (17.5\% and $40.3 \%$ ) (a statistically significant treatment effect in the 6- and 24 -month post-release $(-10.3 \%$ and $-12.4 \%)$ ).

Because the average sentence length differed greatly between offenders in our treatment and control condition, which may have affected post-release re-offending behavior, a logistic regression analyses were performed in which sentence length was added as a covariate (see Table 7). Outcomes showed that, after controlling for sentence length, there was no significant (weighted) treatment effect of standard program treatment group membership in the 6 months following release. However, completing a standard treatment program did decrease re-offending rates 24-month post-release (odds ratio $=0.57)$.

\section{The Impact of a Standard Treatment Program, Plus Cognitive Skill Training}

Table 8 shows the un-weighted comparison of 6- and 24-month post-release reoffending rates of offenders in the treatment group that completed a standard program plus cognitive skill training and control condition eligible for a standard program plus cognitive skill training.

As shown, offenders in the treatment group were not less often re-charged in the 6 and 24 months following release (15.8\% and 50.6\%), compared to those in the control condition $(26.7 \%$ and $64.0 \%)$, since post-release treatment effects were not statistically significant. A weighted comparison between the treatment group (standard program

Table 6 Un-weighted and weighted treatment effects, treatment group $(n=206)$ vs. control group $(n=140)$, standard program

\begin{tabular}{|c|c|c|c|c|c|c|c|}
\hline & \multirow[b]{2}{*}{$\begin{array}{l}\text { Treatment } \\
\text { group }\end{array}$} & \multicolumn{3}{|c|}{ Un-weighted } & \multicolumn{3}{|c|}{ Weighted } \\
\hline & & $\begin{array}{l}\text { Control } \\
\text { group }\end{array}$ & $\begin{array}{l}\text { Treatment } \\
\text { effect }\end{array}$ & Odds ratio & $\begin{array}{l}\text { Control } \\
\text { group }\end{array}$ & $\begin{array}{l}\text { Treatment } \\
\text { effect }\end{array}$ & $\begin{array}{l}\text { Odds } \\
\text { ratio }\end{array}$ \\
\hline $\begin{array}{l}\text { 6-month post-release } \\
\text { recidivism }\end{array}$ & 17.5 & 24.3 & $-7.8 \%$ & .660 (n.s.) & 27.8 & $-10.3 \%$ & $.551(*)$ \\
\hline $\begin{array}{l}\text { 24-month post-release } \\
\text { recidivism }\end{array}$ & 40.3 & 50.7 & $-10.4 \%$ & $.656(*)$ & 52.7 & $-12.4 \%$ & $.606(*)$ \\
\hline
\end{tabular}

Note: $* p \leq .05, * * p \leq .01, * * * p \leq .001$ 
Table 7 Weighted logistic regression analyses on post-release recidivism, standard program $(n=346)$

\begin{tabular}{|c|c|c|c|c|c|c|}
\hline & \multicolumn{3}{|c|}{$\begin{array}{l}\text { 6-month post-release recidivism } \\
\text { (yes vs. no) }\end{array}$} & \multicolumn{3}{|c|}{$\begin{array}{l}\text { 24-month post-release recidivism } \\
\text { (yes vs. no) }\end{array}$} \\
\hline & OR & CI & $p$ & OR & $\mathrm{CI}$ & $p$ \\
\hline Total sentence imposed (in months) & 0.97 & {$[0.94-0.99]$} & $*$ & 0.98 & {$[0.97-1.00]$} & $*$ \\
\hline Treatment group membership & 0.63 & {$[0.36-1.09]$} & n.s. & 0.57 & {$[0.36-0.90]$} & $*$ \\
\hline
\end{tabular}

$* p<.05 * * p<.01 * * * p<.001$

Note: Overall 6-month model Wald $\chi^{2}(13.207,2), p<.05$, Cox and Snell $R^{2}=.040$, Nagelkerke $R^{2}=.063$ Note: Overall 24-month model Wald $\chi^{2}(12.877,2), p<.01$, Cox and Snell $R^{2}=.039$, Nagelkerke $R^{2}=.053$

plus cognitive skill training) and control group (standard program plus cognitive skill training) was also conducted. Results of this weighted comparison pointed out that offenders in the control condition were re-charged more often 6-month post-release (28.1\%), compared to offenders that did receive treatment (15.8\%), indicating a significant treatment effect of $-12.3 \%$. A weighted comparison on 24-month postrelease re-offending rates did not show a significant treatment effect.

Again, a logistic regression analyses were performed in which sentence length was added as a covariate (since sentence length was not included in our weighting procedure), the results of which are presented in Table 9. Outcomes showed that, after controlling for sentence length, there was no significant (weighted) treatment effect of standard program plus cognitive skill training, on re-offending rates in the 6 and 24 months following release. This indicated that engagement in the PoR program, in which an offender was allocated to cognitive skill training, had no effect on the reoffending behavior of program completers.

\section{The Impact of a Standard Treatment Program, Plus Lifestyle Training}

The un-weighted comparison of 6- and 24-month post-release re-offending rates of offenders in the treatment group that completed a standard program plus lifestyle training, and control condition eligible for a standard program plus lifestyle training is shown in Table 10. As reported, offenders in the treatment group were re-charged

Table 8 Un-weighted and weighted treatment effects, treatment group $(n=95)$ vs. control group $(n=75)$, standard program plus cognitive skill training

\begin{tabular}{|c|c|c|c|c|c|c|c|}
\hline & \multirow[b]{2}{*}{$\begin{array}{l}\text { Treatment } \\
\text { group }\end{array}$} & \multicolumn{3}{|c|}{ Un-weighted } & \multicolumn{3}{|l|}{ Weighted } \\
\hline & & $\begin{array}{l}\text { Control } \\
\text { group }\end{array}$ & $\begin{array}{l}\text { Treatment } \\
\text { effect }\end{array}$ & Odds ratio & $\begin{array}{l}\text { Control } \\
\text { group }\end{array}$ & $\begin{array}{l}\text { Treatment } \\
\text { effect }\end{array}$ & Odds ratio \\
\hline $\begin{array}{l}\text { 6-month post-release } \\
\text { recidivism }\end{array}$ & 15.8 & 26.7 & $-10.9 \%$ & .516 (n.s.) & 28.1 & $-12.3 \%$ & $.480(*)$ \\
\hline $\begin{array}{l}\text { 24-month post-release } \\
\text { recidivism }\end{array}$ & 50.5 & 64.0 & $-13.5 \%$ & .574 (n.s.) & 59.2 & $-8.7 \%$ & .705 (n.s.) \\
\hline
\end{tabular}

Note: $* p \leq .05, * * p \leq .01, * * * p \leq .001$ 
Table 9 Weighted logistic regression analyses on post-release recidivism, standard program plus cognitive skill training $(n=170)$

\begin{tabular}{|c|c|c|c|c|c|c|}
\hline & \multicolumn{3}{|c|}{$\begin{array}{l}\text { 6-month post-release recidivism } \\
\text { (yes) }\end{array}$} & \multicolumn{3}{|c|}{$\begin{array}{l}\text { 24-month post-release recidivism } \\
\text { (yes) }\end{array}$} \\
\hline & OR & $\mathrm{CI}$ & $p$ & OR & $\mathrm{CI}$ & $p$ \\
\hline Total sentence imposed (in months) & 0.95 & {$[0.97-1.03]$} & n.s. & 0.98 & {$[0.96-1.01]$} & n.s. \\
\hline Treatment group membership & 0.45 & {$[0.20-1.02]$} & n.s. & 0.81 & {$[0.42-1.58]$} & n.s. \\
\hline
\end{tabular}

$p<.05, * * p<.01, * * * p<.001$

Note: Overall 6-month model Wald $\chi^{2}(4.108,2), p=$ n.s., Cox and Snell $R^{2}=.025$, Nagelkerke $R^{2}=.039$

Note: Overall 24-month model Wald $\chi^{2}(3.282,2), p=$ n.s., Cox and Snell $R^{2}=.020$, Nagelkerke $R^{2}=.026$

less often in the 6 and 24 months after being released from prison (22.2\% and 55.6\%), compared to those in the control condition (39.7\% and 61.5\%), a treatment effect (17.5 and -5.9 ) shown statistically significant for the 6-month post-release period, but not for the 24-month period post-release. Next, a weighted comparison between the treatment group (standard program plus lifestyle training) and control group (standard program plus lifestyles training) was also conducted. The results of this weighted comparison indicated no significant treatment effect. Offenders in the control condition were not re-charged more or less often in the 6- and 24-month post-imprisonment, compared to offenders that did receive treatment.

Again, a logistic regression analyses were performed in which sentence length was added as a covariate. The results of this analysis are presented in Table 11, in which it is shown that, after controlling for sentence length, a significant (weighted) treatment effect of standard program, plus lifestyle training was not documented. This accounted for recidivism rates in the 6-month post-release, as well as re-offending behavior 24 months after release from prison. These results indicate no effect of engagement in the PoR program, if this included being allocated to lifestyle training.

Table 10 Un-weighted and weighted treatment effects, treatment group $(n=63)$ vs. control group $(n=78)$, standard program plus lifestyle training

\begin{tabular}{|c|c|c|c|c|c|c|c|}
\hline & \multirow[b]{2}{*}{$\begin{array}{l}\text { Treatment } \\
\text { group }\end{array}$} & \multicolumn{3}{|c|}{ Un-weighted } & \multicolumn{3}{|c|}{ Weighted } \\
\hline & & $\begin{array}{l}\text { Control } \\
\text { group }\end{array}$ & $\begin{array}{l}\text { Treatment } \\
\text { effect }\end{array}$ & Odds ratio & $\begin{array}{l}\text { Control } \\
\text { group }\end{array}$ & $\begin{array}{l}\text { Treatment } \\
\text { effect }\end{array}$ & Odds ratio \\
\hline $\begin{array}{l}\text { 6-month } \\
\text { post-release } \\
\text { recidivism }\end{array}$ & 22.2 & 39.7 & $-17.5 \%$ & $.433(*)$ & 32.9 & $-10.7 \%$ & .583 (n.s.) \\
\hline $\begin{array}{l}\text { 24-month } \\
\text { post-release } \\
\text { recidivism }\end{array}$ & 55.6 & 61.5 & $-5.9 \%$ & .781 (n.s.) & 60.3 & $-4.4 \%$ & .822 (n.s.) \\
\hline
\end{tabular}

Note: $* p \leq .05, * * p \leq .01, * * * p \leq .001$ 
Table 11 Weighted logistic regression analyses on post-release recidivism, standard program plus lifestyle training $(n=141)$

\begin{tabular}{|c|c|c|c|c|c|c|}
\hline & \multicolumn{3}{|c|}{$\begin{array}{l}\text { 6-month post-release recidivism } \\
\text { (yes) }\end{array}$} & \multicolumn{3}{|c|}{$\begin{array}{l}\text { 24-month post-release recidivism } \\
\text { (yes) }\end{array}$} \\
\hline & OR & CI & $p$ & OR & $\mathrm{CI}$ & $p$ \\
\hline Total sentence imposed (in months) & 0.97 & {$[0.93-1.01]$} & n.s. & 0.96 & {$[0.93-0.99]$} & $*$ \\
\hline Treatment group membership & 0.75 & {$[0.33-1.71]$} & n.s. & 1.18 & {$[0.55-2.53]$} & n.s. \\
\hline
\end{tabular}

$* p<.05, * * p<.01, * * * p<.001$

Note: Overall 6-month model Wald $\chi^{2}(3.924,2), p=$ n.s., Cox and Snell $R^{2}=.029$, Nagelkerke $R^{2}=.042$

Note: Overall 24-month model Wald $\chi^{2}(7.023,2), p<.05$, Cox and Snell $R^{2}=.051$ Nagelkerke $R^{2}=.069$

\section{Additional Analyses}

As shown in previous studies (e.g., $[9,10]$ ), prison-based treatment participants are not always allocated appropriate treatment, in line with risk and need assessment outcomes. Because this could potentially influence treatment outcomes, it was assessed if correctly and incorrectly classified offenders (treatment groups 4, 5, 6, and 7) differed with respect to 6- and 24-month post-release re-offending rates. Classification (correct and incorrect) was determined based on risk and need assessment outcomes and treatments in- and exclusion criteria. In detail, offenders should be referred to cognitive skill training if the overall risk for re-offending is moderate to high, evidenced by a score of at least 32; there are cognitive deficits, evidenced by a weighted score on the RISc-scale thinking and behavior of at least 4; and an offender is not excluded based on additional grounds1 [60]. Offenders should be allocated to lifestyle training if they have drug-, alcohol-, and or gambling-abuse problems, evidenced by a score on the RISc-scale drug misuse of at least 3, and/or alcohol misuse of at least 2, and or financial management and income of at least 5, with a minimal score of 2 on item 5.4, who are not excluded on additional grounds (SVG [84]). Other, more general criteria accounting for both types of treatment include being older than 18, having sufficient Dutch language skills and not being detained under hospital orders; however, offenders in our research group had already qualified for entry and therefore already qualified on these grounds. As shown in Table 12, correctly and incorrectly classified program completers did not differ in registered re-offending behavior, both 6- and 24-month post-release. This indicates that classification errors did not influence (a lack in) treatment effects.

Second, in order to overcome potential concerns relating to the limited number of subjects in our treatment and control groups, and to try and confirm the findings of our analyses using proportional weighting within strata, a logistic regression analysis was conducted. In this logistic regression model, it was tested if treatment group membership was related to post-release re-offending in the 6 and 24-month post-release. In order to do so, three treatment groups were formed; our previously assigned treatment group 2 (see Fig. 1), consisting of prisoners who had been selected for treatment, but who did not enter treatment due to organizational circumstances $(n=265$, coded 0$)$; our previously assigned treatment group 4 , consisting of prisoners who had completed a standard treatment program $(n=206$, coded 1$)$; and the previously assigned treatment 
Table 12 6- and 24-month post-release recidivism rates of correctly and incorrectly classified program completers $(n=344)$

\begin{tabular}{lllll}
\hline & $\begin{array}{c}\text { Correctly classified program } \\
\text { completers }(n=163)\end{array}$ & $\begin{array}{l}\text { Incorrectly classified program } \\
\text { completers }(n=181)\end{array}$ & $\begin{array}{c}\text { T o t a } 1 \\
(n=344)\end{array}$ \\
\hline & $\%$ & $\%$ & $\%$ & $p$ \\
$\begin{array}{l}\text { 6-month post-release re- } \\
\text { cidivism (yes) }\end{array}$ & 19.6 & 17.1 & 18.6 & n.s. \\
$\begin{array}{c}\text { 24-month post-release re- } \\
\text { cidivism (yes) }\end{array}$ & 43.6 & 47.1 & 45.3 & n.s. \\
\hline
\end{tabular}

$* p<.05, * * p<.01, * * * p<.001$

groups 5, 6, and 7, consisting of prisoners who completed a standard program combined with criminogenic-need specific treatment $(n=138$, coded 2$)$. The covariates included in the logistic regression model were age, ethnicity, age of onset; number of prior convictions for a violent crime (ever and in the last 5 years); number of prior convictions for a property crime (ever and in the last 5 years); number of prior convictions for other crimes (ever and in the last 5 years); and number of previous prison sentences (ever and in the last 5 years), offense type, sentence length, and risk for future re-offending. As shown in Table 13 (only showing the parameters of the testing variables included), the outcomes of our logistic regression analysis confirmed the previously documented findings, that no significant treatment effect was found.

\section{Discussion}

The purpose of the current study was to examine to what extent the Dutch Prevention of Recidivism Program is effective in reducing post-release re-offending among program participants. The research question was addressed by analyzing various sources of data on a population-based sample of males that were incarcerated in The Netherlands. To optimally minimize concerns regarding selection effects that may have occurred by

Table 13 Logistic regression analyses 6- and 24-month post-release recidivism rates $(n=609)$

\begin{tabular}{|c|c|c|c|c|}
\hline & \multicolumn{2}{|c|}{$\begin{array}{l}\text { 6-month post-release } \\
\text { recidivism (yes) }\end{array}$} & \multicolumn{2}{|c|}{$\begin{array}{l}\text { 24-month post-release } \\
\text { recidivism (yes) }\end{array}$} \\
\hline & OR & $p$ & OR & $p$ \\
\hline \multicolumn{5}{|l|}{ Treatment group membership } \\
\hline No re-integration plan formed 'organizational' $(n=265)$ & ref & ref & ref & ref \\
\hline Completed standard program $(n=206)$ & 1.45 & n.s. & 1.19 & n.s. \\
\hline Completed standard program plus treatment $(n=138)$ & 0.87 & n.s. & 0.67 & n.s. \\
\hline
\end{tabular}

$* p<.05, * * p<.01, * * * p<.001$

Note: Overall 24-month model Wald $\chi^{2}(68.442,20), p<.001$, Cox and Snell $R^{2}=.106$ Nagelkerke $R^{2}=.162$ 
confounding covariates, treatment effectiveness was studied by applying proportional weighting within strata.

\section{The Effectiveness of the Prevention of Recidivism Program}

Based on the theoretical framework brought forward, it was expected that ex-detainees who had engaged in the prison-based PoR program would re-offended less postincarceration, compared to offenders that had not engaged in treatment during their time in prison. Additionally, it was expected that for offenders in need of treatment (i.e., cognitive skill training or lifestyle training) would benefit from engagement in criminogenic need-specific treatment modules aimed to reduce their post-release recidivism rates by decreasing their criminogenic needs relating to cognitive skill deficits and/or addiction problems.

To assess this, the group of program completers was compared to an appropriate control group of offenders that were eligible for treatment, but could not participate due to organizational circumstances, by use of proportional weighting within strata. In order to test if the type of treatment program attained was shown to impact outcomes, a group of program completers that completed a standard program was compared to a control group of offenders that were, based on risk and need scores, eligible for a standard program, while program participants that completed a standard program plus cognitive skill training were compared to a control group consisting of offenders eligible for standard treatment plus cognitive skill training, and finally, a group of offenders that completed a standard program plus lifestyle training were compared to a group of nonparticipants that were eligible for standard program plus lifestyle training.

Study results showed that prisoners who completed a standard treatment program, re-offended significantly less in the 24-month post-release, compared to offenders in the control condition. This treatment effect was not found when comparing prisoners who completed a standard program plus cognitive skill training and for those who completed a standard program plus lifestyle training. The above-mentioned results lead to the conclusion that participation in the prison-based PoR program appears to reduce re-offending behavior in the 24 months following release from prison, for offenders who had engaged in a standard program that did not include any behavioral treatment modules.

The overall effect, with respect to the impact of a prison-based treatment program, was partly as hypothesized, since a weighted effect of treatment (standard program) was found when a group of completers was compared to an appropriate control group, indicating perhaps a small effect of phased re-entry. An effect was not found when conducting a-more traditional-logistic regression analysis. The fact that risk and need-oriented programs were unsuccessful was not as expected. In conclusion, the current study did not appear to provide any substantial evidence concerning the hypothesized relationship between prison-based treatment and post-release reoffending. These findings were inconsistent with premises made based on the RiskNeed-Responsivity model of crime prevention and correctional rehabilitation [5] as well as previous studies.

The first question that rises is why phased re-entry (the only potentially effective element of a standard treatment program) was in part effective in reducing post-release recidivism for prisoners referred to standard treatment, but not for offenders who were 
referred to a standard treatment program with criminogenic need-specific treatment. It could be argued that prisoners who were referred to a standard treatment program represent a group of participants with a less severe criminogenic-need profile (since they were not referred to any treatment program). Perhaps phased re-entry was more beneficial to them, compared to offenders with a more complex criminogenic need profile, or more profound problems.

We must also wonder why criminogenic need-specific treatment programs, found fairly successful in many previous studies, did not reach a treatment effect. A few possible explanations (though these may not be exhaustive) can be thought of. First of all, previous studies have indicated that adhering to the principles of risk, need, and responsivity is important to reach an optimal treatment effect. However, previous work also stated that a rehabilitation program should be implemented and conducted in practice as it was designed - the principle of treatment integrity [4, 38, 49, 61]. As the PoR program was designed in line with the RNR model, a positive treatment effect was expected. However, a lack in program integrity (optimal selection of participants, proper referrals to treatment, proper trained treatment staff) may have caused the absence of a larger effect. Second, perhaps the treatment programs applied in light of the PoR program do not, or only to a limited extent, sufficiently reduce an in many cases rather broad risk and need spectrum. For example, a program may improve cognitive skills, but perhaps that is insufficient to achieve a substantial risk and need (and subsequently recidivism) reduction. Unfortunately, these alternative explanations could not be studied.

A third possible explanation for the current study's moderate findings may lie in the fact that the criminal justice system in The Netherlands differs from those in other parts of the (Western) world. Many correctional rehabilitation programs had been developed and studied in countries with a different sentencing system, where conditions of confinement may be different (harsher) and where prison sentences may be a lot longer than is the case in The Netherlands (about 75\% of all offenders in Dutch prisons are incarcerated for a period of less than 3 months; see [24]). Consequently, incarceration circumstances in The Netherlands may be different compared to offenders in other parts of the world. This more humane system $[74,76]$ could perhaps in itself affect existing risk factors, or may perhaps prevent deterioration of needs.

A fourth possibility, explaining the considerably small/and lack in treatment effect found, may be the fact that the control group, offenders that were eligible but could not participate because of organizational circumstances, may have been engaged in treatment activities after they had been (conditionally) released. This could have potentially caused a decline in recidivism rates among prisoners in the control group. However, previous research had indicated that post-release treatment is only imposed for a rather modest proportion of conditionally released detainees [42], making it perhaps improbable that a large proportion of our control group had been engaged in post-release treatment. Nevertheless, certain influence of post-release treatment programs cannot be ruled out.

\section{Study Limitations and Strengths}

The current study investigated the effectiveness of the PoR program in The Netherlands. Such a study has, to date, not been conducted and this work therefore 
represents a major advancement in the field of correctional (prison-based) rehabilitation research. Also, a statistical technique was applied that made it possible to optimally account for confounding covariates, so that comparable control groups could be created. There are, however, some limitations that are worthy to be mentioned and that deserve attention in future research.

A first shortcoming lies in the study's quasi-experimental design, which has limitations due to the fact that subject were not randomly assigned to the treatment and control conditions. And although the current study, using proportional weighting within strata, was able to create balance on a large number of covariates, it cannot be ruled out that other (unobservable) factors have influenced treatment group membership as well as post-release re-offending outcomes. A second limitation that may have hampered the current study was the fact that we were not able to fully take into account the matter of program integrity. The PoR program is tailored to the specific needs of each offender, but some specific programs may have been executed better than others. Large differences in program integrity may have had an influence on post-release re-offending outcomes, which we did not include in the current study. A previous study has indicated that there are some implementation and execution issues that hamper an optimal performance of the PoR program, such as a suboptimal cooperation between the prison service and probation service, and delays in individual program trajectories as a result of the complex program structure [40], but since we were not able to include these measures of integrity, these factors could not be properly controlled for. Third, although this study could make use of a large, nation-wide, population-based research group consisting of almost 4000 detainees, the final research samples were relatively small because detainees were divided among several treatment modalities. The fact that the final research group was rather small is perhaps as much an outcome of this study (apparently not many offenders in the Netherlands get to engage in treatment) as it is a shortcoming. Although we have statistically tested the effectiveness of treatment in various ways, we cannot rule out that the lack in treatment effects found was not influenced by our modest treatment groups. Finally, the results of the current study only apply to male detainees in The Netherlands, who were incarcerated for a maximum time of 38 months. The results can therefore not be transferred to, for example, offenders with a longer prison sentence.

\section{Conclusions and Directions for Future Research}

To conclude, this study does not provide convincing evidence concerning the effectiveness of a nation-wide prison-based rehabilitation program implemented in The Netherlands. The results merely seem to indicate that participation in this program leads to a moderate decrease in post-release re-offending rates among offenders that completed a standard program, i.e., a program that did not include any risk and need oriented treatment modules. However, as mentioned, the current study was the first to look into the re-offending behavior of program participants. Besides the fact that only one study has been conducted, the current study may have been hampered by some limitations caused by design and data availability. Far-reaching policy implications therefore are premature. It appears essential to further examine the effectiveness of prison-based treatment in The Netherlands in future studies, optimally using randomized controlled design. 
On a final note, it must be mentioned that the numbers presented in this study raise an additional concern: Most offenders in The Netherlands do not (get to) engage in prison-based treatment. Using a population-based sample, this study has shown that only 344 of 3.981 prisoners $(8.6 \%)$ re-entered society having had engaged in any type of formal treatment (most of which were not engaged in any criminogenic need-specific treatment program), because most prisoners were not eligible for treatment due to rather strict legal inclusion criteria. As a previous study on the same sample has shown [8], those prisoners not eligible for treatment represent an equally high-risk group as those who are, and are therefore in equally high need for treatment, but are excluded based on (in most cases) sentence length. Additionally, non-participation and non-completion that resulted from organizational circumstances were also substantial. Needless to say, this type of program attrition is perhaps the most unwanted type of drop-out, since it is not instigated by the offender, and means prisoners are deprived from their right to engage in re-socialization activities (as granted to them by section 2 of the Dutch Penitentiary Principles Act).

Funding Information The Prison Project is financially supported by the University of Leiden, the Netherlands Institute for the Study of Crime and Law Enforcement (NSCR), the Netherlands Organization for Scientific Research (NWO), and Utrecht University.

\section{Compliance with Ethical Standards}

The study was approved by the Ethical Committee for Legal and Criminological research of the VU University, Amsterdam.

Open Access This article is licensed under a Creative Commons Attribution 4.0 International License, which permits use, sharing, adaptation, distribution and reproduction in any medium or format, as long as you give appropriate credit to the original author(s) and the source, provide a link to the Creative Commons licence, and indicate if changes were made. The images or other third party material in this article are included in the article's Creative Commons licence, unless indicated otherwise in a credit line to the material. If material is not included in the article's Creative Commons licence and your intended use is not permitted by statutory regulation or exceeds the permitted use, you will need to obtain permission directly from the copyright holder. To view a copy of this licence, visit http://creativecommons.org/licenses/by/4.0/.

\section{References}

1. Adviesbureau van Montfoort \& Reclassering Nederland. (2004). RISc versie 1.0. Recidive Inschattingsschalen. Handleiding [RISc version 1.0 Recidivism Assessment Scales, Manual]. Utrecht: Reclassering Nederland.

2. Alexander, B. K. (1984). When experimental psychology is not empirical enough: the case of the exposure orientation. Canadian Psychology, 25(2), 84-95.

3. Andrews, D. A., \& Bonta, J. (1994-2016). The psychology of criminal conduct. Cincinnati: Anderson.

4. Andrews, D. A., \& Dowden, C. (2005). Managing correctional treatment for reduced recidivism: a metaanalytic review of program integrity. Legal and Criminological Psychology, 10(2), 173-187.

5. Andrews, D. A., Bonta, J., \& Hoge, R. D. (1990). Classification for effective rehabilitation: rediscovering psychology. Criminal Justice and Behavior, 17(1), 19-52.

6. Andrews, D. A., Bonta, J., \& Wormith, J. S. (2011). The risk-need-responsivity (RNR) model: Does adding the good lives model contribute to effective crime prevention? Criminal Justice and Behavior, 38(7), 735-755. 
7. Anonymized. (2013). Rehabilitatie in Nederlandse gevangenissen: Wat is de stand van zaken ten aanzien van de uitvoering en doelmatigheid van het programma Terugdringen Recidive? [Rehabilitation in Dutch prisons: The state of the art concerning a prison-based treatment program in The Netherlands]. Tijdschrift voor Veiligheid, 12(3), 3-19.

8. Anonymized (2017). Targeting recidivism: an evaluation study into the functioning and effectiveness of a prison-based treatment program (doctoral dissertation). Leiden: Meijers Research Institute and Graduate School of the Leiden Law School.

9. Anonymized. (2018a). Selection Processes in Prison-Based Treatment Referrals: A Street-Level Bureaucracy Perspective. Crime \& Delinquency, 64(8), 1001-1032.

10. Anonymized. (2018b). Cohort profile: the prison project - a study of criminal behavior and life circumstances before, during, and after imprisonment in the Netherlands. Journal of Developmental and Life-Course Criminology, 4(1), 120-135.

11. Austin, P. C. (2011). An introduction to propensity score methods for reducing the effects of confounding in observational studies. Multivariate Behavioral Research, 46(3), 399-424.

12. Baay, P., Liem, M., \& Nieuwbeerta, P. (2012). "Ex-imprisoned homicide offenders: once bitten, twice shy?" the effect of the length of imprisonment on recidivism for homicide offenders. Homicide Studies, 16(3), 259-279.

13. Bandura, A. (1986). Social foundations of thought and action: a social cognitive theory. Englewood Cliffs: Prentice-Hall.

14. Beerthuizen, M. G. C. J., Beijersbergen, K. A., Noordhuizen, S., \& Weijters, G. (2015). Vierde meting van de monitor nazorg ex-gedetineerden. Den Haag: Wetenschappelijk Onderzoek-en Documentatiecentrum, Ministerie van Veiligheid en Justitie.

15. Binswanger, I. A., Stern, M. F., Deyo, R. A., Heagerty, P. J., Cheadle, A., Elmore, J. G., \& Koepsell, T. D. (2007). Release from prison, a high risk of death for former inmates. New England Journal of Medicine, 356(2), 157-165.

16. Binswanger, I. A., Krueger, P. M., \& Steiner, J. F. (2009). Prevalence of chronic medical conditions among jail and prison inmates in the USA compared with the general population. Journal of Epidemiology and Community Health, 63(11), 912-919.

17. Bonta, J. (2002). Offender risk assessment: guidelines for selection and use. Criminal Justice and Behavior, 29(4), 355-379.

18. Bonta, J., \& Andrews, D. A. (2007). Risk-need-responsivity model for offender assessment and rehabilitation. Ottawa: Public Safety Canada.

19. Clark, D. A. (2000). Theory manual for enhanced thinking skills (prepared for the joint prison probation accreditation panel). London: National Probation Directorate.

20. Clemmer, D. (1940). The prison community. New York: Christopher.

21. Collins, J. J. (1981). Drinking and crime: perspectives on the relationships between alcohol consumption and criminal behavior. Guilford Press.

22. Collins, J. J., \& Messerschmidt, P. M. (1993). Epidemiology of alcohol-related violence. Alcohol Research and Health, 17(2), 93.

23. de Jongste, W. M., \& Decae, R. J. (2010). De competentie van enkelvoudige kamers in strafzaken verruimd [the competence of single-judge chambers in criminal cases expanded]. Den Haag: WODC.

24. De Looff, J., Van de Haar, M., Van Gemmert, N., \& Valstar, H. (2017). DJI in Getal 2012-2016. Den Haag: DJI.

25. Dutch Prison Service \& Dutch Probation Organizations. (2007). Programma terugdringen recidive: draaiboek samenwerking gevangeniswezen en reclassering [the prevention of recidivism program: Manual on collaboration between prison and probation organizations]. Den Haag: DJI.

26. Fagan, J. (1990). Intoxication and aggression. Crime and Justice, 13, 241-320.

27. Farrington, D. P., Gottfredson, D. C., Sherman, L. W., \& Welsh, B. C. (2002). The Maryland scientific methods scale. In L. W. Sherman, B. C. Welsh, D. Farrington, \& D. L. MacKenze (Eds.), Evidence-based crime prevention (pp. 13-21). London: Routledge.

28. Fazel, S., \& Wolf, A. (2015). A systematic review of criminal recidivism rates worldwide: current difficulties and recommendations for best practice. PLoS One, 10(6), e0130390.

29. Friendship, C., Blud, L., Erikson, M., \& Travers, R. (2002). An evaluation of cognitive behavioural treatment for prisoners. London: Home Office.

30. Geller, A., \& Curtis, M. A. (2011). A sort of homecoming: Incarceration and the housing security of urban men. Social Science Research, 40(4), 1196-1213.

31. Goggin, C., \& Gendreau, P. (2006). The implementation and maintenance of quality services in offender rehabilitation programmes. In C. R. Hollin \& E. J. Palmer (Eds.), Offending behaviour programmes: development, application and controversies (pp. 209-246). Chichester: John Wiley \& Sons. 
32. Goldstein, P. J. (1985). The drugs/violence nexus: a tripartite conceptual framework. Journal of Drug Issues, 15(4), 493-506.

33. Gottlieb, P., \& Gabrielsen, G. (1990). The future of homicide offenders: results from a homicide project in Copenhagen. International Journal of Law and Psychiatry, 13(3), 191-205.

34. Hagan, J., \& Dinovitzer, R. (1999). Collateral consequences of imprisonment for children, communities and prisoners. Crime and Justice, 26, 121-162.

35. Hammett, T. M. (2001). Making the case for health interventions in correctional facilities. Journal of Urban Health, 78(2), 236-240.

36. Hannah-Moffat, K. (2005). Criminogenic needs and the transformative risk subject: hybridizations of risk/need in penality. Punishment \& Society, 7(1), 29-51.

37. Hirschi, T. (1969). Causes of delinquency. Berkeley: University of California Press.

38. Hollin, C. R. (1995). The meaning and implications of programme integrity. In J. McGuire (Ed.), What works: reducing reoffending - guidelines from research and practice (pp. 193-206). Chichester: Wiley.

39. Howard, P., Clark, D., \& Garnham, N. (2003). An Evaluation and Validation of the Offender Assessment System (OASys). Londen: OASys Central Research Unit.

40. Inspectorate of Security and Justice. (2010). Samenwerkingsmodel Terugdringen Recidive [Cooperation model Prevention of Recidivism Program]. Den Haag: Inspectorate of Security and Justice.

41. Irvin, J. E., Bowers, C. A., Dunn, M. E., \& Wang, M. C. (1999). Efficacy of relapse prevention: a metaanalytic review. Journal of Consulting and Clinical Psychology, 67(4), 563-570.

42. Jacobs, M. J. G., Van Kalmthout, A. M., \& Von Bergh, M. Y. W. (2006). Toepassing van bijzondere voorwaarden bij voorwaardelijke vrijheidsstraf en schorsing van de voorlopige hechtenis bij volwassenen [Implementation of special conditions in conditional releases and suspensions of pre-trial detentions among adults]. IVA beleidsonderzoek en advies: Universiteit Tilburg.

43. Jolley, M. J., \& Kerbs, J. J. (2010). Risk, need, and responsivity: Unrealized potential for the international delivery of substance abuse treatment in prison. International Criminal Justice Review, 20(3), 280-301.

44. Joy Tong, L. S., \& Farrington, D. P. (2006). How effective is the reasoning and rehabilitation programme in reducing reoffending? A meta-analysis of evaluations in four countries. Psychology, Crime \& Law, 12(1), 3-24.

45. Joy Tong, L. S., \& Farrington, D. P. (2008). Effectiveness of reasoning and rehabilitation in reducing reoffending. Psicothema, 20(1), 20-28.

46. Latessa, E. J. (2004). The challenge of change: correctional programs and evidence based practices. Criminology \& Public Policy, 3(4), 547-560.

47. Latessa, E. J., Cullen, F. T., \& Gendreau, P. (2002). Beyond correctional quackery: professionalism and the possibility of effective treatment. Federal Probation, 66, 43.

48. Laub, J. H., \& Sampson, R. J. (1993). Turning points in the life course: why change matters to the study of crime. Criminology, 31(3), 301-325.

49. Leschied, A. W., Bernfeld, G. A., \& Farrington, D. P. (2001). Implementation issues. In G. A. Bernfeld, D. P. Farrington, \& A. W. Leschied (Eds.), Offender rehabilitation in practice: implementing and evaluating effective programs (pp. 3-24). Chichester: Wiley.

50. Lipsey, M. W., \& Cullen, F. T. (2007). The effectiveness of correctional rehabilitation: a review of systematic reviews. The Annual Review of Law and Social Science, 3, 297-320.

51. Lipsey, M. W., Chapman, G. L., \& Landenberger, N. A. (2001). Cognitive-behavioral programs for offenders. The Annals of the American Academy of Political and Social Science, 578(1), 144-157.

52. Loughran, T. A., Mulvey, E. P., Schubert, C. A., Fagan, J., Piquero, A. R., \& Losoya, S. H. (2009). Estimating a dose-response relationship between length of stay and future recidivism in serious juvenile offenders. Criminology, 47(3), 699-740.

53. Lynch, J. P., \& Sabol, W. J. (2001). Prisoner re-entry in perspective. Washington DC: The Urban Institute.

54. Marlatt, G. A., \& Gordon, J. R. (1985). Relapse prevention: maintenance strategies in the treatment of addictive behaviors. New York: Guilford Press.

55. McGrath, R. J., Cumming, G., Livingston, J. A., \& Hoke, S. E. (2003). Outcome of a treatment program for adult sex offenders: from prison to community. Journal of Interpersonal Violence, 18(1), 3-17.

56. McGuire, J. (2004). Understanding psychology and crime: perspectives on theory and action. Berkshire: Open University Press.

57. McGuire, J. (2005). The think first programme. In M. McMurran \& J. McGuire (Eds.), Social problem solving and offending (pp. 183-206). Chichester: Wiley.

58. McMurran, M., \& Theodosi, E. (2007). Is offender treatment non-completion associated with increased reconviction over no treatment? Psychology, Crime, and Law, 13(4), 333-343. 
59. McSweeney, T., Turnbull, P. J., \& Hough, M. (2008). The treatment and supervision of drug-dependent offenders: a review of the literature prepared for the UK Drug Policy Commission. London: UK Drug Policy Commission.

60. Ministry of Justice. (2007). De theoretische handleiding van de training voor cognitieve vaardigheden [theoretical manual of the cognitive skill training]. Den Haag: Ministerie van Justitie.

61. Moncher, F. J., \& Prinze, R. J. (1991). Treatment fidelity in outcome studies. Clinical Psychology Review, 11(3), 247-266.

62. Orsagh, T., \& Chen, J. R. (1988). The effect of time served on recidivism: an interdisciplinary theory. Journal of Quantitative Criminology, 4(2), 155-171.

63. Petersilia, J. (2000). When prisoners return to communities: political economic and social consequences. Federal Probation, 65(1), 3-8.

64. Polaschek, D. L. (2010). Treatment non-completion in high-risk violent offenders: looking beyond criminal risk and criminogenic needs. Psychology, Crime \& Law, 16(6), 525-540.

65. Posner, M. A., \& Ash, A. S. (2012). Comparing weighting methods in propensity score analysis. Columbia University: Unpublished working paper.

66. Ramakers, A., Apel, R., Nieuwbeerta, P., Dirkzwager, A., \& Van Wilsem, J. (2014). Imprisonment length and post-prison employment prospects. Criminology, 52(3), 399-427.

67. Raphael, S. (2011). Incarceration and prisoner reentry in the United States. The Annals of the American Academy of Political and Social Science, 635(1), 192-215.

68. Roberts, A. R., Zgoba, K. M., \& Shahidullah, S. M. (2007). Recidivism among four types of homicide offenders: an exploratory analysis of 336 homicide offenders in New Jersey. Aggression and Violent Behavior, 12(5), 493-507.

69. Robinson, D. (1995). The impact of cognitive skills training on post-release recidivism among Canadian federal offenders. Ottawa: Correctional Service Canada.

70. Ross, R. R., \& Fabiano, E. A. (1985). Time to think: a cognitive model of delinquency prevention and offender rehabilitation. Johnson City: Institute of Social Science \& Arts Incorporated.

71. Ross, R. R., \& Fabiano, E. (1990). Reasoning and rehabilitation course instructors manual. Ottawa: Cognitive Station.

72. Sadlier, G. (2010). Evaluation of the impact of the HM prison service enhanced thinking skills programme on reoffending. London: Ministry of Justice.

73. Smith, P., Gendreau, P., \& Goggin, C. (2002). The effects of prison sentences and intermediate sanctions on recidivism: general effects and individual differences. Ottawa: Solicitor General Canada.

74. Snacken, S. (2010). Resisting punitiveness in Europe? Theoretical Criminology, 14(3), 273-292.

75. Snodgrass, G. M., Blokland, A. A., Haviland, A., Nieuwbeerta, P., \& Nagin, D. S. (2011). Does the time cause the crime? An examination of the relationship between time served and reoffending in the Netherlands. Criminology, 49(4), 1149-1194.

76. Subramanian, R., \& Shames, A. (2013). Sentencing and prison practices in Germany and The Netherlands. Center on Sentencing and Corrections. Vera Institute of Justice.

77. Sutherland, E. H. (1939). Principles of criminology. New York: Lippincott.

78. Ten Velden, F. S., \& De Wilde, T. R. W. (2013). Rechterlijke groepsbesluitvorming [Judicial group decision-making]. In W. H. Van Boom, I. Giesen, \& A. J. Verheij (Eds.), Capita civilologie: handboek voor empirie en privaatrecht [Capita Civilology: handbook for empirics and private law]. Den Haag: Boom Juridische Uitgevers.

79. Travers, R., Wakeling, H. C., Mann, R. E., \& Hollin, C. R. (2013). Reconviction following a cognitive skills intervention: an alternative quasi-experimental methodology. Legal and Criminological Psychology, 18(1), 48-65.

80. Travis, J., Solomon, A. L., \& Waul, M. (2001). From prison to home: the dimensions and consequences of prisoner reentry. Washington DC: The Urban Institute.

81. Van der Knaap, L. M., Alberda, D. L., Oosterveld, P., \& Born, M. P. (2012). The predictive validity of criminogenic needs for male and female offenders: comparing the relative impact of needs in predicting recidivism. Law and Human Behavior, 36(5), 413.

82. van der Knaap, L. M., Leenarts, L. E. W., Born, M. P., \& Oosterveld, P. (2012). Re-evaluating inter-rater reliability in offender risk assessment. Crime \& Delinquency, 58(1), 147-163.

83. van der Linden, B. (2004). Terugdringen Recidive [The Prevention of Recidivism Program]. Proces, 83, 94-101.

84. Verslavingsreclassering, S. V. G. (2009). Leefstijltraining voor verslaafde justitiabelen. Deel A: Theoretische en managementhandleiding [Lifestyletraining for addicted offenders. Part A: Theoretical and manangement instruction]. Utrecht: SVG Verslavingsreclassering. 
85. Virkkunen, M., \& Linnoila, M. (1993). Brain serotonin, type II alcoholism and impulsive violence. Journal of Studies on Alcohol, Supplement, 11, 163-169.

86. Wermink, H., Nieuwbeerta, P., Ramakers, A. A., de Keijser, J. W., \& Dirkzwager, A. J. (2018). Shortterm effects of imprisonment length on recidivism in the Netherlands. Crime \& Delinquency, 64(8), 1057-1093.

87. Western, B., Kling, J. R., \& Weiman, D. F. (2001). The labor market consequences of incarceration. Crime \& Delinquency, 47(3), 410-427.

88. Wexler, H. K., De Leon, G., Thomas, G., Kressel, D., \& Peters, J. (1999). The amity prison TC evaluation reincarceration outcomes. Criminal Justice and Behavior, 26(2), 147-167.

89. White, H. R. (1990). The drug use-delinquency connection in adolescence. Cincinatti: National Institute on Alcohol Abuse and Alcoholism.

90. White, H. R., \& Gorman, D. M. (2000). Dynamics of the drug-crime relationship. Criminal justice, 1(15), $151-218$.

91. White, H. R., Brick, J., \& Hansell, S. (1993). A longitudinal investigation of alcohol use and aggression in adolescence. Journal of Studies on Alcohol, Supplement, 11, 62-77.

92. Winship, C., \& Morgan, S. L. (1999). The estimation of causal effects from observational data. Annual Review of Sociology, 25, 659-706.

93. Worling, J. R., \& Curwen, T. (2000). Adolescent sexual offender recidivism: success of specialized treatment and implications or risk prediction. Child Abuse and Neglect, 24(7), 965-982.

94. Wormith, J. S., \& Olver, M. E. (2002). Offender treatment attrition and its relationship with risk, need, responsivity and recidivism. Criminal Justice and Behavior, 29(4), 447-471.

Publisher's Note Springer Nature remains neutral with regard to jurisdictional claims in published maps and institutional affiliations.

\section{Affiliations}

\section{Anouk Q. Bosma ${ }^{1}$ • Maarten J. J. Kunst ${ }^{1}$ • Anja J. E. Dirkzwager ${ }^{2}$ • Paul Nieuwbeerta ${ }^{1}$}

1 Institute of Criminal Law and Criminology, Leiden University, PO Box 9500, 2300 RA Leiden, The Netherlands

2 Netherlands Institute for the Study of Crime and Law Enforcement (NSCR), PO Box 71304, 1008 BH Amsterdam, The Netherlands 